\title{
Heterojunction oxide thin-film transistors
}

A book chapter in:

Semiconducting Metal Oxide Thin-Film Transistors

Authors:

Hendrik Faber (https://orcid.org/0000-0002-4918-2365)

Emre Yarali

Emre Yengel (https://orcid.org/0000-0001-7208-4803 )

Thomas D. Anthopoulos* (http://orcid.org/0000-0002-0978-8813) 


\section{Contents}

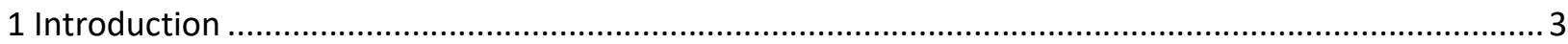

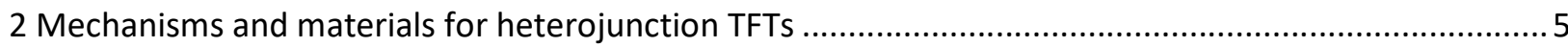

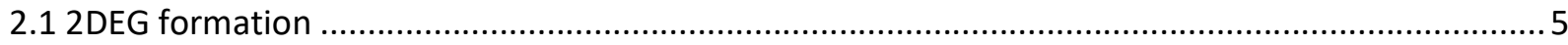

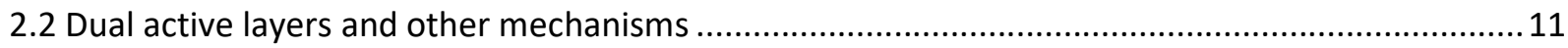

3. TFTs based on bilayer heterojunctions and multilayer stacks ......................................................... 14

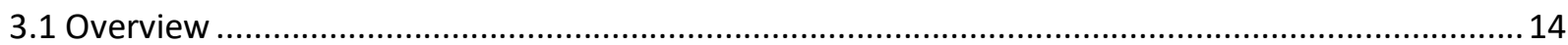

3.2 Distinct heterojunction layers versus mixed phase oxides...................................................... 18

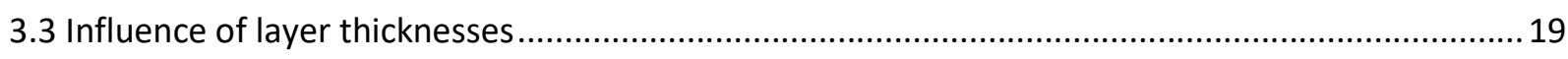

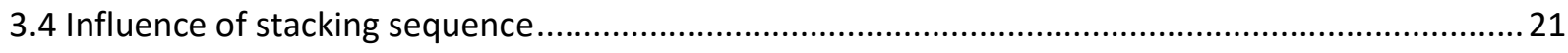

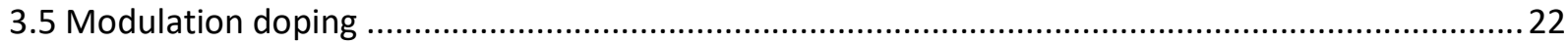

4 Improvements in bias stress stability for heterojunction TFTs..........................................................24

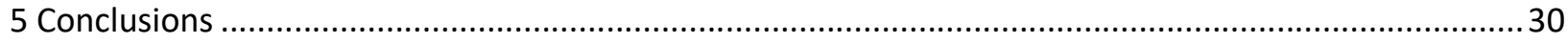

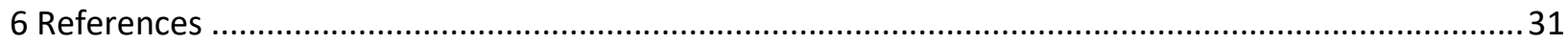

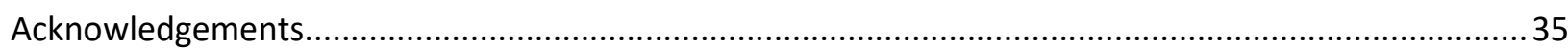




\section{Introduction}

Metal oxide (MO) semiconductors find widespread application in a variety of (opto)electronic devices due to a multitude of beneficial properties. Transparency and high electron mobility together with decent environmental stability, non-toxicity, and a range of possible deposition schemes have made them an excellent material class for thin-film transistor (TFTs) applications of all kinds, with specific emphasis on display technologies for (consumer) electronics (1-3). Target requirements in this field are a high charge carrier mobility $\mu_{F E}$, which allows small pixel sizes and fast refresh rates that can cope even with demanding applications e.g. in virtual reality displays, as well as good stability during continuous use cases over extended time periods. Both requirements should ideally be met using materials and fabrication methods that are cost-effective and easily applicable over large areas. Aside from chasing this goal via optimizing individual materials, through composition and process control, another approach that has gained attention in the recent years is to make use of active channels composed of layers of two or more different MO materials (4-6). These heterojunction (HJ) films can lead to remarkable device properties when integrated into TFTs, allowing the improvement of both targets, $\mu_{F E}$ and bias stability, simultaneously. In many cases, the HJ TFTs achieve better results than either of the individual MO films is capable of.

The proposed reasons and mechanisms for an improved performance that will be discussed in the course of this chapter may vary from case to case. Among them are the creation of a two dimensional electron gas (2DEG) at the $\mathrm{HJ}(7)$, the combination of positive properties of individual MO layers while mitigating their drawbacks (8), the control of chemical composition, stoichiometry and morphology as well as interplays between them.

When referring to metal oxide $\mathrm{HJ}$ films there is a number of terms that can be found in literature, e.g. bilayer metal oxide (BMO) (9), dual active layer (DAL) $(10,11)$, double-active layer (12) stacked active layer 
(SAL) (13), or (quasi)-superlattice (14-16). Especially the latter two expressions hint at the fact that the number of layers in a $\mathrm{HJ}$ film is not limited to two, but that multiple layers of different MOs can be stacked together. In addition to multilayers, this chapter also discusses reports of homojunction films where the respective layers feature nominally the same material (e.g. IGZO) which were processed in a way to create distinct properties per layer (17-21).

Heterojunction films are created by sequential deposition of the individual components. In the literature, different naming conventions can be found when describing the sequence of a bilayer film. While describing a film stack of $\ln _{2} \mathrm{O}_{3} / \mathrm{ZnO}$, for one research group this refers to the sequence starting from the substrate, i.e. an $\ln _{2} \mathrm{O}_{3}$ is being deposited first onto the substrate, followed by $\mathrm{ZnO}$ layer on top. Other authors, however, may use the same term $\left(\ln _{2} \mathrm{O}_{3} / \mathrm{ZnO}\right)$ to refer to the opposite stacking direction, starting with the material on the very top. To avoid possible confusion, throughout this chapter we will be using the first naming convention that describes layers according to the sequence in which they are deposited, as depicted schematically in Figure 1. Another way to refer to individual films is by the names front channel and back channel, whereas front channel is the film directly at the interface with the dielectric and the back channel is the film facing away from the dielectric, typically in contact with the environment or a passivation layer for the bottom-gate top-contact device architecture. Due to the multitude of different metal oxides and their combinations in ternary or higher compound materials, abbreviation such as IGZO for indium gallium zinc oxide will be used hereafter. In these abbreviations, the following letter-element combinations will be employed: I for Indium, G for Gallium, Z for Zinc, T for Tin, A for Aluminium, H for Hafnium, O for Oxide. Among the material pairings within the HJs, there can be found junctions between insulator/insulator (22), semiconductor/semiconductor $(14,23,24)$, or semiconductor/insulator (15, 2528).

In the course of this chapter we will first take a look at the underlying mechanisms for the improved devices performances caused by $\mathrm{HJ}$ metal oxide (HJMO) films, as well as typical material combination and 
deposition techniques used to process the HJs (section 2). Next, section 3 is providing a general overview of HJMO TFTs and their field-effect mobility $\mu_{\mathrm{FE}}$ as the main figure of merit. It then goes on describing examples how specific parameters, such as film thickness ratio or film stacking sequence in $\mathrm{HJ}$ and multilayer TFTs, can have an impact on the device characteristics. Finally, section 4 showcases the effects that $\mathrm{HJ}$ channels have to offer in regards to bias stress stability followed by the conclusion and outlook section 5 .

MO1 / MO2

Heterojunction:

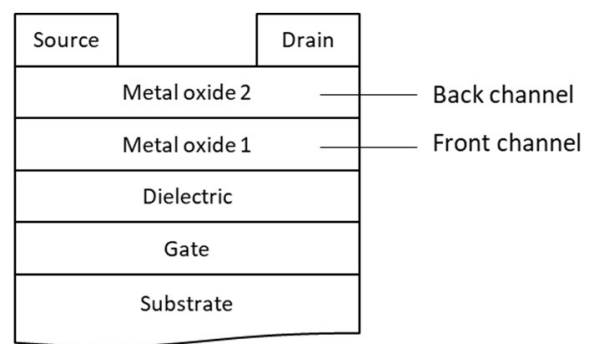

Figure 1: Naming convention for heterojunction film stacks as part of a TFT. The expression MO1/MO2 refers to metal oxide 1 being the first film to be deposited onto the substrate or dielectric and metal oxide 2 being the top layer.

\section{Mechanisms and materials for heterojunction TFTs}

\subsection{DEG formation}

A single semiconductor channel material will always be bound to its inherent limitations when it comes to charge carrier mobility, but the combination of two or more materials allows the exploitation of interface effects that enable new transport properties as well as mobility values that surpass those measured for the individual $\mathrm{HJ}$ components. Joining two materials with differently sized bandgaps and a large enough conduction band offset $\Delta \mathrm{E}_{\mathrm{C}}$ can lead to the formation of a potential well at the heterointerface in which electrons are confined and can form a 2-dimensional electron gas (2DEG). This 
phenomenon has been shown in epitaxially grown HJs based on e.g. GaAs/AIGaAs (29) or AlGaN/GaN (30). An additional electron transfer into the potential well can be initiated by a process called modulation doping (MOD) where the barrier layer is intentionally doped. This results in an increased electron density in the 2DEG and, importantly, it physically separates the ionized donors from the charge carriers. As a consequence, the effects of impurity scattering are all but eliminated which allows the carrier mobility to reach larger value than that measured for the bulk semiconductors that form the $\mathrm{HJ}(29,31)$.

For oxide based materials, 2DEG formation has been reported e.g. for heterojunctions based on the insulating perovskite oxides $\mathrm{SrTiO}_{3}$ and $\mathrm{LaAlO}_{3}$ (22) as well as for $\mathrm{ZnO} / \mathrm{ZnMgO}$ (32-34). While the alternating $\mathrm{AO}$ and $\mathrm{BO}_{2}$ planes that define the perovskite structure are charge neutral for the case of $\mathrm{SrTiO}_{3}\left(\mathrm{Sr}^{2+} \mathrm{O}^{2-}\right.$ and $\left.\mathrm{Ti}^{4+}\left(\mathrm{O}^{2-}\right)_{2}\right)$ they either carry one positive or negative charge for $\mathrm{LaAlO}_{3}\left(\mathrm{La}^{3+} \mathrm{O}^{2-}\right.$ and $\left.\mathrm{Al}^{3+}\left(\mathrm{O}^{2-}\right)_{2}\right)$. This leaves the $\mathrm{HJ}$ of $\mathrm{SrTiO}_{3} / \mathrm{LaAlO}_{3}$ with either half an extra electron or hole per unit cell that can be transferred across the interface where it is spatially confined (4). Ohtomo et al. investigated $\mathrm{SrTiO}_{3} / \mathrm{LaAlO}_{3} \mathrm{HJ}$ deposited by pulsed laser deposition (PLD) (22). They reported that the junction formed by $\mathrm{Al}^{3+}\left(\mathrm{O}^{2-}\right)_{2} / \mathrm{Sr}^{2+} \mathrm{O}^{2-}$ remains an insulator, however, if the junction is formed by $\mathrm{La}^{3+} \mathrm{O}^{2-}$ and $\mathrm{Ti}^{4+}\left(\mathrm{O}^{2-}\right)_{2}$ it shows $\mathrm{n}$-type conductivity and a high Hall mobility $\mu_{H}$ above $10,000 \mathrm{~cm}^{2} / \mathrm{Vs}$ measured at $2 \mathrm{~K}$. The polarity discontinuation at the interface was proposed as the main mechanism for the electron transfer and 2DEG creation.

The formation of a 2DEG in the $\mathrm{ZnO} / \mathrm{ZnMgO}$ system was reported as early as 2003 . Edahiro et al. used PLD to grow a $\mathrm{ZnMgO} / \mathrm{ZnO} \mathrm{HJ}$ on a sapphire substrate and as a result found a high sheet carrier concentration of $8.8 \times 10^{12} \mathrm{~cm}^{-2}$ and a clear bump in carrier density at the location of interface, revealed by capacitancevoltage (C-V) carrier profiling (32). A high room temperature (RT) Hall mobility $\mu_{H}$ of $130 \mathrm{~cm}^{2} /$ vs was determined, which increased further for reduced temperatures down to $100 \mathrm{~K}$ then remained stable and featured a value of $360 \mathrm{~cm}^{2} / \mathrm{Vs}$ at $1.85 \mathrm{~K}$. This temperature dependant behaviour was indicative of suppressed ionized impurity scattering as compared to a single ZnO layer, whose mobility fell drastically 
for $T<100 \mathrm{~K}$. Additionally, clear Shubnikov-de Haas $(\mathrm{SdH})$ oscillations were observed in magnetoresistance measurements at $1.85 \mathrm{~K}$. In 2004, Koike et al. realized a double heterojunction of $\mathrm{ZnMgO} / \mathrm{ZnO} / \mathrm{ZnMgO}$, grown by molecular beam epitaxy (MBE) on sapphire (35). A deep potential well was formed as a result of the large conduction band discontinuity $\Delta \mathrm{E}_{\mathrm{c}}$ of $0.9 \mathrm{eV}$ between both oxides. The lattice mismatch between $\mathrm{ZnO}$ and $\mathrm{ZnMgO}$ lead to a polarization induced high sheet charge and the accumulation of free electrons to form the 2DEG at the interface. Hall effect measurements deduced an electron density of $1.2 \times 10^{13} \mathrm{~cm}^{-2}$ as well as $\mu_{H}$ of 170 and $400 \mathrm{~cm}^{2} / \mathrm{Vs}$ at RT and $77 \mathrm{~K}$, respectively. Tampo et al. altered the MBE conditions to successfully grow the $\mathrm{HJ}$ on $\mathrm{Zn}$ polar faces of $\mathrm{ZnO}$ where it was previously only possible to use the $O$ polar surface $(23,36)$. This resulted in a boost in $\mu_{H}$ with a value of $250 \mathrm{~cm}^{2} / \mathrm{Vs}$ at RT and up to $2750 \mathrm{~cm}^{2} / \mathrm{Vs}$ at $4 \mathrm{~K}$. Further refinement of the $\mathrm{Mg}$ content later improved $\mu_{\mathrm{H}}$ to $319 \mathrm{~cm}^{2} / \mathrm{Vs}$ at RT (7). In work by Nakano et al. (37), the authors report a ZnO/ZnMgO HJ grown by MBE on $\mathrm{Zn}$ faced (0001) ZnO substrates, where a conductive polymer is spin cast on top of the stack to act as a Schottky contact. This allowed field-controlled measurements of Hall mobility with a value up to $21,000 \mathrm{~cm}^{2} / \mathrm{Vs}$ at $2 \mathrm{~K}$. This value was further increased in studies by Tzukasaki et al. who were able to observe fractional quantum Hall effect in a $\mathrm{ZnO} / \mathrm{ZnMgO} \mathrm{HJ}$ and reached $\mu_{\mathrm{H}}$ of $180,000 \mathrm{~cm}^{2} / \mathrm{Vs}$ at $0.06 \mathrm{~K}$ (33) as well as a report by Falson et al, who measured a maximum $\mu_{H}$ of $700,000 \mathrm{~cm}^{2} / \mathrm{Vs}$ at $0.5 \mathrm{~K}$ in films with a very dilute $\mathrm{Mg}$ concentration (38).

Collectively, the early investigations pointed out a number of properties that are exemplary for the formation of a $2 \mathrm{DEG}$. Among those are a high conduction band offset $\Delta \mathrm{E}_{\mathrm{c}}$ to confine the electrons at the $\mathrm{HJ}$ (Figure 2a), typically a high sheet carrier density on the order of $10^{12}-10^{13} \mathrm{~cm}^{-2}$ which is largely independent of temperature, and a clear peak in the cross-sectional carrier profile at the location of the $\mathrm{HJ}$ (Figure $2 \mathrm{~b}, \mathrm{c}$ ). Additionally, the importance of a high quality and flat interface of the $\mathrm{HJ}$ was highlighted $(7,39)$. Further, the mobility was found to be increasing with decreasing temperature in contrast to a 
mobility decline at low temperatures for a single layer ZnO. Finally, HJs that formed a 2DEG showed SdH oscillations at low temperature magnetoresistance measurements (inset in Figure 2c).

The first transistors using a $\mathrm{MO} \mathrm{HJ}$ with a $2 \mathrm{DEG}$ in the $\mathrm{ZnO} / \mathrm{ZnMgO}$ system were demonstrated between 2005 and 2007 by Koike et al. (40) and Sasa et al. (41, 42). All cases used MBE to grow the channel materials on top of sapphire substrates and employed a top-gate device architecture with $\mathrm{MgO}, \mathrm{Al}_{2} \mathrm{O}_{3}$ or $\mathrm{HfO}_{2}$ as gate dielectrics and mobilities $\mu_{\mathrm{FE}}$ between 62 and $240 \mathrm{~cm}^{2} / \mathrm{Vs}$ were achieved. Despite the exceptionally high mobility values, a drawback for practical applications of these structures was the low drain current on/off ratio that stayed below $10^{3}$.

a

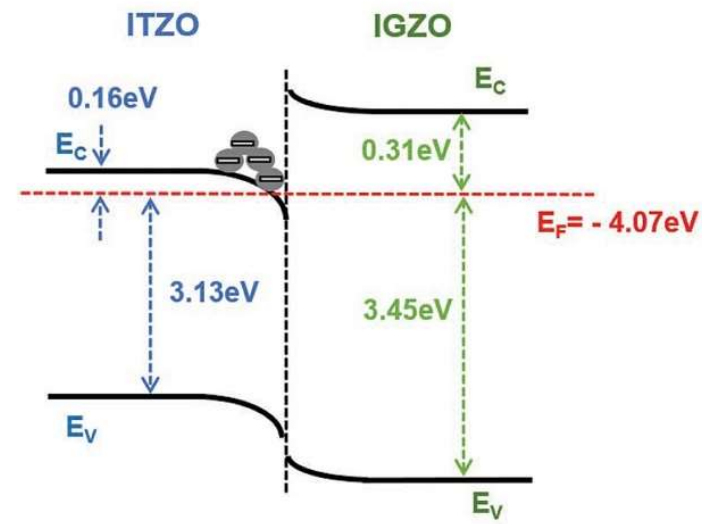

C

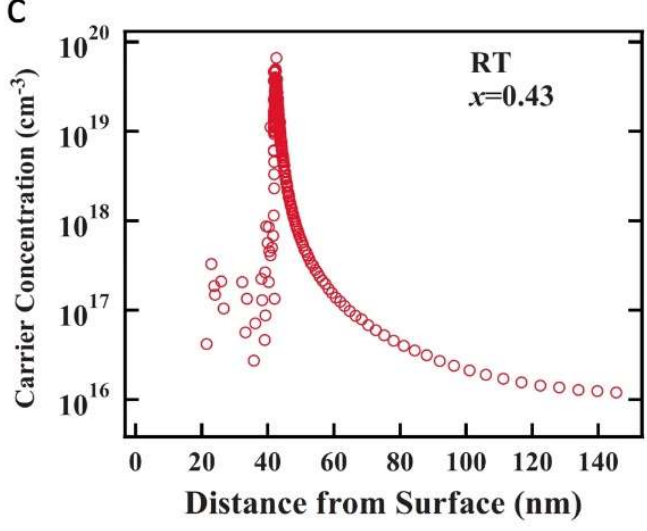

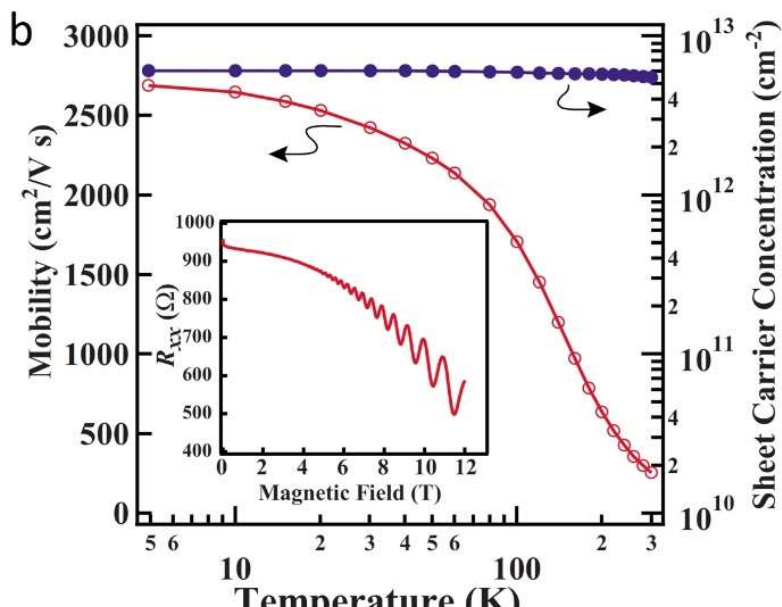

d

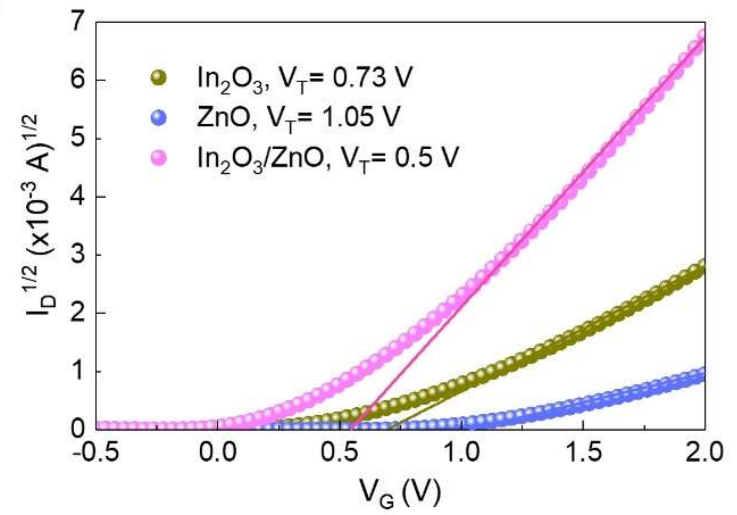

Figure 2: Properties observed for 2DEGs HJ films. a) Band diagram of ITZO/IGZO HJ with proposed 2DEG formation. The band offset makes it favourable for electrons to accumulate at the HJ interface. Reproduced with permission. (43) Copyright 2018, John Wiley and Sons. b) Electron carrier concentration across a $\mathrm{ZnO} / \mathrm{ZnMgO} \mathrm{HJ} \mathrm{cross-section} \mathrm{in} \mathrm{the} \mathrm{direction} \mathrm{from} \mathrm{the} \mathrm{top}$ surface towards the substrate. A clear spike in carrier concentration indicates the location of the 2DEG at the interface of the HJ. Reprinted from (7), with the permission of AIP Publishing. c) Temperature dependent mobility and sheet carrier concentration 
for a $\mathrm{ZnO} / \mathrm{ZnMgO}$ system. The inset shows SdH oscillations in magnetoresistance measurements at $0.5 \mathrm{~K}$. Reprinted from (7), with the permission of AIP Publishing. d) Plot of square root of drain current vs gate voltage for solution processed $\mathrm{ZnO}, 1 n_{2} \mathrm{O}_{3}$ and bilayer $\ln _{2} \mathrm{O}_{3} / \mathrm{ZnO}$ TFTs. The HJ device features improved performance over both individual MO films. Reproduced with permission. (44) Copyright 2020, John Wiley and Sons.

In 2010, the first experiments were carried out to confirm that 2DEGs could be obtained with other deposition methods that did not rely on epitaxial growth on special substrates. Chin et al. used RF sputtering to fabricate $\mathrm{HJs}$ of $\mathrm{ZnO} / \mathrm{ZnMgO}$ on glass substrates and despite the polycrystalline nature of the films observed 2DEG characteristics, such as a high sheet carrier density, which increased to a maximum around $1 \times 10^{14} \mathrm{~cm}^{-2}$ with increasing $\mathrm{Mg}$ content due to increased polarization (45). Additionally, both the carrier density and the Hall mobility were found to be approximately temperature independent. It was argued that the high carrier density of the 2DEG could successfully screen the grain boundary potential (46) but that improvements in surface roughness were required to increase the only moderate $\mu_{\mathrm{H}}$ of $39.4 \mathrm{~cm}^{2} / \mathrm{Vs}$. The same approach of sputtered $\mathrm{ZnO} / \mathrm{ZnMgO}$ was integrated by Cheng et al. to produce top-gated $\mathrm{HJ}$ TFTs with $\mathrm{Al}_{2} \mathrm{O}_{3}$ dielectric and achieved a high $\mu_{\mathrm{FE}}$ of $84.2 \mathrm{~cm}^{2} / \mathrm{Vs}$ while maintaining a large on/off ratio $>10^{6}$, indicating the practical applicability of polycrystalline metal oxide HJs forming 2DEGs (47). Similarly, Remashan et al. used metal organic chemical vapor deposition (MOCVD) to grow polycrystalline $\mathrm{ZnO}$ on top of a $\mathrm{ZnMgO}$ layer and reported an increased $\mu_{\mathrm{FE}}$ of the HJ TFT of $9.1 \mathrm{~cm}^{2} /$ Vs compared to a single layer of $\mathrm{ZnO}\left(2.3 \mathrm{~cm}^{2} / \mathrm{Vs}\right)(48)$.

The two dimensional nature of electrons was also described in materials systems other than crystalline $\mathrm{ZnO} / \mathrm{ZnMgO}$, for example for a thin polycrystalline ITO layer on top of amorphous IGZO or in superlattices based on $\mathrm{ZnO}$ and $\mathrm{Al}_{2} \mathrm{O}_{3}(15,49)$. Taniguchi et al. described a type 2 band offset for their sputter deposited IGZO/ITO heterojunction that favors electron transport from the ITO conduction band to that of IGZO and the 2D nature of electrons was assigned based on temperature dependent Hall effect measurements (49). Resulting HJ TFTs achieved a $\mu_{\mathrm{FE}}$ of $20 \mathrm{~cm}^{2} /$ Vs compared to $7.5 \mathrm{~cm}^{2} /$ Vs for a single layer of IGZO. On the other hand, Ahn et al. produced semiconductor/dielectric superlattices by atomic layer deposition (ALD) 
of $\mathrm{ZnO} / \mathrm{Al}_{2} \mathrm{O}_{3}$ at moderate $200{ }^{\circ} \mathrm{C}$ on common $\mathrm{Si} / \mathrm{SiO}_{2}$ substrates (15). $\mathrm{ZnO}$ films grown on alumina showed improved crystallinity and preferred c-axis orientation compared to $\mathrm{ZnO}$ grown on the bare substrate. Together with the $2 \mathrm{D}$ confinement of electrons in the $\mathrm{ZnO}$ layers due to the large $\mathrm{Al}_{2} \mathrm{O}_{3}$ band gap, this superlattice channel showed enhanced mobility $\left(27.8 \mathrm{~cm}^{2} / \mathrm{Vs}\right)$ and on/off ratio $\left(10^{9}\right)$ compared to $\mathrm{ZnO}$ only devices, as well as improved bias stress behavior.

After 2DEG formation had been observed even for imperfect, polycrystalline vacuum deposited films, the question arose if similar effects could also be realized with solution processing methods. To this end, Lin et al. developed $\ln _{2} \mathrm{O}_{3} / \mathrm{ZnO}$ HJs based on ultrathin $(<10 \mathrm{~nm})$ films processed via spin coating of precursors and subsequent annealing at moderate temperatures below $200^{\circ} \mathrm{C}(14)$. Due to an offset in Fermi level and conduction band, an electron transfer from $\mathrm{ZnO}$ to $\ln _{2} \mathrm{O}_{3}$ was proposed, where available energy levels are quantized because of the low film thickness, leading to a quasi 2D-electron-gas-like system at the MO $\mathrm{HJ}$. The bilayer structure was extended by adding thin layers of equally solution processed $\mathrm{Ga}_{2} \mathrm{O}_{3}$ to form a quasi superlattice (QSL) system consisting of $\ln _{2} \mathrm{O}_{3} / \mathrm{Ga}_{2} \mathrm{O}_{3} / \mathrm{ZnO} / \mathrm{Ga}_{2} \mathrm{O}_{3} / \mathrm{In}_{2} \mathrm{O}_{3}$. The addition of $\mathrm{Ga}_{2} \mathrm{O}_{3}$ served the purpose to enhance confinement and interface planarity as well as for trap passivation. This QSL setup exhibited high $\mu_{\mathrm{FE}}$ of 30 and $40 \mathrm{~cm}^{2} / \mathrm{Vs}$. using a $\mathrm{SiO}_{2}$ or using a $\mathrm{Al}_{2} \mathrm{O}_{3} / \mathrm{ZrO}_{2}$ bilayer dielectric, respectively. The concept around using discrete solution processed $\ln _{2} \mathrm{O}_{3}$ and $\mathrm{ZnO}$ bilayers was further developed by the same research group, exploring a new solution-based deposition technique (spray pyrolysis) (50), the effects of high temperature annealing up to $600^{\circ} \mathrm{C}(51)$, photonic curing as alternative method for the rapid precursor conversion $(44,52)$, the impact of modulation doping (MOD) through Lidoped $\mathrm{ZnO}$ films (53), the variation in stacking sequence within multilayer junctions (16) and the incorporation of $\mathrm{ZnO}$ nanoparticles and an interlayer of polystyrene for additional trap passivation (54). Several properties that resemble or hint at a 2DEG system were observed repeatedly in these studies, including a spike in electron concentration at the location of the heterojunction (via C-V carrier profiling), a change towards a temperature independent $\mu_{\mathrm{FE}}$ and a shift in transport properties from a trap limited 
conduction (TLC) to a percolation conduction (PC) $(14,16,44,50)$. Additionally, the mobility of the various $\mathrm{HJ}$ structures reached consistently high values between $\approx 20-50 \mathrm{~cm}^{2} / \mathrm{Vs}$, and in all cases was significantly enhanced when compared to TFTs based on either of the individual MO components (as depicted in Figure 2d). This synergetic effect demonstrates the unique properties that can be achieved by two-dimensional systems engineered at metal oxide heterojunctions.

Other solution processed MO bilayer systems for that 2DEG formation was reported include e.g. the combination of ITZO/IGZO (43), $\ln _{2} \mathrm{O}_{3} / \mathrm{AllnO}$ (55), or a homojunction of undoped and polymer doped $\ln _{2} \mathrm{O}_{3}$ (56). Lee et al. first investigated the properties of planar junctions depending on the bottom ITZO layer thickness, and then created a corrugated stripe structure of ITZO/IGZO bilayers with alternating thin/thick IZO bottom layers in the stripes running perpendicular to the channel (43). Here, the thick-IZO/IGZO parts were identified to enhance $\mu_{\mathrm{FE}}$, while the thin-IZO/IGZO parts were able to maintain a low off-current level. This combination resulted in TFTs with high mobility up to $51 \mathrm{~cm}^{2} / V s$ in combination with an on/off ration $>10^{8}$. In the study by Chen et al. the authors used the polymer polyethylenimine (PEI) to dope the back channel $\ln _{2} \mathrm{O}_{3}$ on top of an undoped $\ln _{2} \mathrm{O}_{3}$ front channel (56). The resulting energy offsets gave rise to electron confinement and 2DEG formation. Transistor performance based on $\ln \mathrm{n}_{2} \mathrm{O}_{3} / \mathrm{In}_{2} \mathrm{O}_{3}: \mathrm{PEl}$ surpassed that of single layer $\ln _{2} \mathrm{O}_{3}$ devices and reached mobilities $>10 \mathrm{~cm}^{2} / \mathrm{Vs}$ and as high as $30 \mathrm{~cm}^{2} / \mathrm{Vs}$ using $\mathrm{SiO}_{2}$ or a high-k $\mathrm{ZrO}_{2}$ dielectric, respectively.

\subsection{Dual active layers and other mechanisms}

While HJ layer stacks that form a 2DEG typically lead to TFTs in which the bilayer is showing improved characteristics (e.g. higher mobility and currents, improved bias stability) compared to either of the individual films, another widely used approach to work with layered MOs is to balance out properties of either components $(6,9,21,57)$. In this case, a thin but highly conductive MO with high charge carrier 
density $\mathrm{N}_{\mathrm{e}}$ and mobility $\mu_{\mathrm{FE}}$, typically deposited as the front channel, serves as the main transport layer. By itself, the drain current for this film may be difficult to modulate through the gate voltage resulting in either a negative $V_{\text {th }}$ or even the device not being able to fully turning off. In order to achieve successful gate modulation, a second and more resistive $\mathrm{MO}$ with smaller mobility is used, mostly as the back channel material. Compared to devices based on the front channel material alone, this bilayer combination can have the drawback to reduce the drain current in the on-state slightly but it comes with the substantial benefit that it is now possible to fully turn-off the device. For this combination, the back channel takes control over the turn-on behavior and $V_{t h}$, while the front channel still delivers reasonably high currents and mobility values. Because both layers play their distinctive part in the assembly, the term dual active layer is often used to describe them. An example of this behavior is shown in the transfer characteristics in Figure 3, where a rather conductive $\ln _{2} \mathrm{O}_{3}$ is combined with layer of IGO and the combined solution processed $\mathrm{In}_{2} \mathrm{O}_{3} / \mathrm{IGO}$ bilayer film shares the off-current with IGO yet still delivers an increased $\mathrm{I}_{\mathrm{D}}$ in the onstate (8).
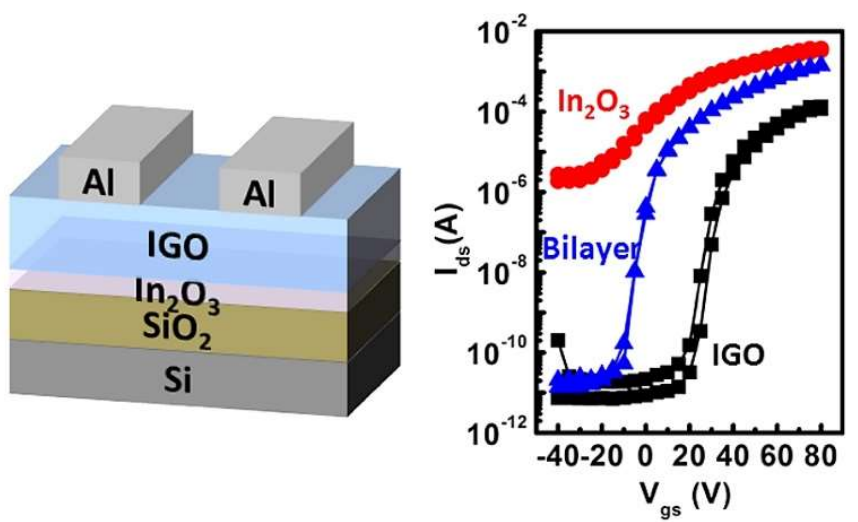

Figure 3: a) Schematic cross-section transfer characteristics of TFTs based on single layer $\ln _{2} \mathrm{O}_{3}$ and IGO as well as their combination in an $\ln _{2} \mathrm{O}_{3} / \mathrm{IGO}$ dual active layer. The bilayer combines beneficial attributes from both components, such as the higher mobility and on-current of the front channel and the low off-current of the back channel material. Reprinted with permission from (8). Copyright 2013 American Chemical Society. 
The approach to use a high mobility transport / high $\mathrm{N}_{\mathrm{e}}$ transport layer with a more stable film to control off-current and $V_{\text {th }}$ has been pursued with a number of metal oxide combinations and different deposition techniques. For sputter deposited HJs this includes e.g. ITO/ZTO (58), IZO/HIZO (59, 60), IZO/IGZO (61) or IGZO:H/IGZO (21). Similarly, solution based dual layer HJ TFTs have been reported based on e.g. IZO/AIZO $(62,63), \ln _{2} \mathrm{O}_{3} / \mathrm{IGO}(8)$, or also indium-free composition of $\mathrm{SnO} / \mathrm{ZnO}(64)$.

Other reasons to employ a bilayer $\mathrm{HJ}$ include the control and improvement of chemical composition, stoichiometry or morphology. For example, as reported for sputtered as well as solution processed back channels of tin containing materials, i.e. IZO/ZTO (65), IGZO/ITO (10) or IGZO/ZTO (11), the diffusion of $\mathrm{Sn}^{4+}$ into the respective bottom layer could lead to improvements in device performance. The tin cations served as n-dopants by substituting for $\mathrm{In}^{3+}, \mathrm{Ga}^{3+}$ or $\mathrm{Zn}^{2+}$, thus increasing the carrier concentration in the channel.

Metal oxide films deposited by various solution processes may still possess a considerable degree of porosity as well as pinholes which are detrimental to an efficient charge transport. Consequently, the subsequent application of a second $\mathrm{MO}$ layer has the chance to fill up gaps in the bottom layer and thus help to improve the channel properties. This beneficial effect was observed for spin cast ZTO films deposited on top of IGZO $(10,11)$, as well as for inkjet printed $\mathrm{ZTO} / \mathrm{In}_{2} \mathrm{O}_{3}$ bilayers in the study by Lee $e t$ al., who reported film densification through pore filling and passivation as well as reduced surface roughness leading to improved $\mu_{\mathrm{FE}}$ in devices (12).

In a rare example of p-type metal oxide $\mathrm{HJs}$, Al-Jawhari et al. conducted a study on $\mathrm{SnO} / \mathrm{Cu}_{2} \mathrm{O}$ TFTs, where the $\mathrm{Cu}_{2} \mathrm{O}$ capping layer could be used to help control the $\mathrm{SnO}$ stoichiometry (66). Depending on the oxygen pressure during sputter deposition, the layer thickness ratios, and annealing temperatures between 140 and $200^{\circ} \mathrm{C}$, the resulting TFTs were either found to exhibit $\mathrm{n}$-type behavior, $\mathrm{p}$-type behavior or no 
functionality. With the correct parameter set, an improved p-type mobility of $0.66 \mathrm{~cm}^{2} /$ Vs could be established compared to $0.23 \mathrm{~cm}^{2} / \mathrm{Vs}$ for a single film of $\mathrm{SnO}$.

It is worth noting that the various possible origins for improved device characteristics of HJ TFTs described here in section 2 do not have to be seen as isolated mechanisms. Rather, a combination of several of them acting simultaneously may be responsible and the exact root cause determination for enhanced charge transport properties may not always be possible.

\section{TFTs based on bilayer heterojunctions and multilayer stacks}

\subsection{Overview}

Before looking at a few specific examples how the properties of HJMO TFTs can be tailored, Figure 4 is showing an overview of mobility values that were reported to date, with respect to the deposition methods and maximum substrate temperature (Figure 4a) as well as the year of publication (Figure 4b). The data used to generate Figure 4 is additionally listed in Table 1 and Table 2 . In these plots, the distinction between deposition categories is as follows. Molecular beam epitaxy (MBE), pulsed laser deposition (PLD), and (plasma enhanced) atomic layer deposition (PEALD) are considered advanced vacuum techniques, all sputtering variations as well as metal-organic chemical vapour deposition (MOCVD) are grouped as vacuum techniques, whereas methods such as spin coating, spray pyrolysis (50, $67)$ or inkjet printing $(12,68)$ are in the solution processing category.

The largest range of $\mu_{\mathrm{FE}}$ is found within the advanced vacuum category with values between 6.5 for a $\mathrm{In}_{2} \mathrm{O}_{3} / \mathrm{ZnO} \mathrm{HJ}$ and $240 \mathrm{~cm}^{2} / \mathrm{Vs}$ for $\mathrm{ZnO} / \mathrm{ZnMgO}(42,69)$, with the latter value being close to Hall effect mobility of $250 \mathrm{~cm}^{2} / \mathrm{Vs}$ measured in a comparable $\mathrm{ZnO} / \mathrm{ZnMgO}$ system at RT (23). This large variation can be explained mainly by two factors. First, the deposition temperature can have a major impact on the 
resulting films, where typically higher temperatures lead to films with improved structural quality. Second, especially processes such as MBE require specialized substrates (e.g. sapphire) to reach the full potential of epitaxially grown materials $(7,23,35,40,42)$. Common substrate materials, such as $\mathrm{Si} / \mathrm{SiO}_{2}$, glass etc., are far more commercially viable but do not yield the same quality films $(15,69-71)$. The range as well as maximum of reported mobility in the regular vacuum deposition and solution processing category is considerably smaller with values over $100 \mathrm{~cm}^{2} / \mathrm{Vs}(20,72)$ and close to $50 \mathrm{~cm}^{2} / \mathrm{Vs}(43,51,54)$, respectively. The decline in performance is expected, as especially in the case of solution processing the films typically still contain a significant number of defects that hinder charge transport. Interestingly, there does not seem to be a strong correlation between the maximum temperature and the resulting mobilities for the $\mathrm{HJ}$ films in the vacuum and solution processing deposition categories.
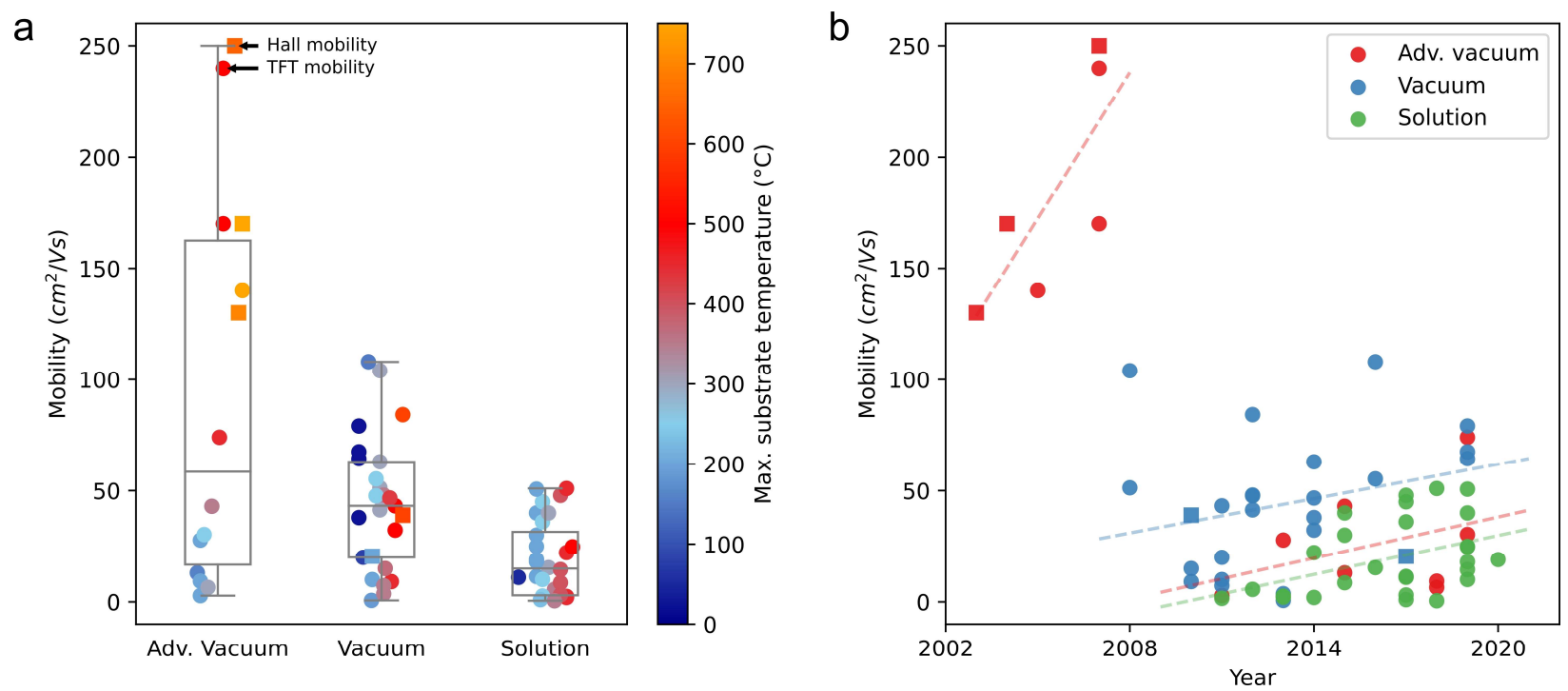

Figure 4: Overview of mobility values achieved in heterojunction metal oxide structures, based on the values listed in Table 1 and Table 2. a) Mobility broken down by deposition categories, i.e. advanced vacuum deposition techniques (MBE, ALD, PLD), vacuum techniques (sputtering and MOCVD) and various solution processing techniques (spin coating, spray pyrolysis, inkjet). The color of each marker is indicative of the maximum substrate temperature during fabrication as shown in the color bar on the right. Within each category, markers are additionally distributed from left to right with increasing maximum temperature. b) Progression of mobility values with the year of publication. Here, the color of each marker denotes the deposition category for the MO semiconductors. The dashed lines are linear trend lines as guides for the eye. In both panels ( $a, b)$, square markers denote mobility values extracted via Hall effect measurements at RT whereas circular markers correspond to device mobility values extracted from TFTs. 
As can be seen in Figure 4b, the initial studies on heterojunctions were started from 2003 to approx. 2008 $(7,23,32,35,40,42)$. Here, techniques such as MBE and PLD were used to grow high quality ZnO/ZnMgO HJ on sapphire substrates; an approach that lead to the highest reported mobility values. From 2008 onwards, it was attempted to reproduce the benefits of $\mathrm{HJ}$ films by more scalable and commercially viable vacuum deposition techniques, predominantly by sputtering on more common substrates $(9,17-21,24$, $28,45,47,49,58-61,65,66,72-74)$. As a result, exceptionally high mobility values over $80 \mathrm{~cm}^{2} / \mathrm{Vs}$ were achieved in the ZnO/ZnMgO (47) system but also for ITO/GIZO (72) and ATZO/ATZO (20) (front and back channel processed with different oxygen pressure). Similarly, for solution processing techniques, research into HJMO TFTs was intensified from 2011 onwards, using spin coating in the vast majority of cases $(8,10$, $11,13,14,16,25,43,44,51-57,62-64,75,76)$, but also including spray pyrolysis $(50,67)$ and inkjet printing $(12,68)$. This increasing shift in research efforts towards large scale and higher throughput fabrication techniques versus the ultrahigh quality epitaxial MO HJs of the initial phase can be seen as the reason why the overall average mobility actually appears to trend downwards over the years. However, if the advanced vacuum category is further divided into periods of epitaxial (before 2009) and polycrystalline growth (after 2009), within all categories the mobility trend-line is actually increasing over time (see dashed lines in Figure 4b).

Table 1: Overview of selected publications on heterojunction metal oxide films and TFTs processed by vacuum techniques. Entries with the added asterisk (*) in the mobility field denote Hall mobilities $\mu_{H}$ rather than TFT device mobilties $\mu_{F E}$.

\begin{tabular}{|c|c|c|c|c|c|c|}
\hline Year & Heterojunction Structure & Deposition Method & Mobility $\left(\mathrm{cm}^{2} / \mathrm{Vs}\right)$ & Dielectric & $\begin{array}{c}\text { Maximum } \\
\text { Temperature }\left({ }^{\circ} \mathrm{C}\right) \\
\end{array}$ & Reference \\
\hline & & $\begin{array}{c}\text { Deposition Category: } \\
\text { Advanced Vacuum }\end{array}$ & & & & \\
\hline 2003 & ZnMnO:Al/ZnO & $P L D$ & $130(*)$ & $n / a$ & 700 & (32) \\
\hline 2004 & $\mathrm{ZnMgO} / \mathrm{ZnO} / \mathrm{ZnMgO}$ & $M B E$ & 170 & $n / a$ & 750 & (35) \\
\hline 2005 & $\mathrm{ZnMgO} / \mathrm{ZnO} / \mathrm{ZnMgO}$ & $M B E$ & 140 & $\mathrm{MgO}$ & 750 & (40) \\
\hline 2007 & $\mathrm{ZnO} / \mathrm{ZnMgO}$ & $M B E$ & $\begin{array}{l}240 \\
170 \\
\end{array}$ & $\begin{array}{l}\mathrm{HfO}_{2} \\
\mathrm{Al}_{2} \mathrm{O}_{3} \\
\end{array}$ & 500 & (42) \\
\hline 2007 & $\mathrm{ZnO} / \mathrm{ZnMgO}$ & $M B E$ & $250(*)$ & $n / a$ & 650 & (23) \\
\hline 2011 & $\mathrm{ZnO} / \mathrm{Al}_{2} \mathrm{O}_{3} / \mathrm{ZnO}$ & PEALD & 2.8 & $\mathrm{Al}_{2} \mathrm{O}_{3}$ & 200 & (26) \\
\hline 2013 & $\mathrm{Al}_{2} \mathrm{O}_{3} / \mathrm{ZnO}$ superlattice & $A L D$ & 27.8 & $\mathrm{SiO}_{2}$ & 200 & (15) \\
\hline 2015 & $\mathrm{ZnO} / \mathrm{SnO}$ multilayers & PLD & 43 & $\mathrm{Al}_{2} \mathrm{O}_{3}$ & 350 & (70) \\
\hline 2015 & $\mathrm{ZnO} / \mathrm{HfO}_{2}$ & $A L D$ & 13 & $\mathrm{HfO}_{2}$ & 160 & (27) \\
\hline
\end{tabular}




\begin{tabular}{|c|c|c|c|c|c|c|}
\hline 2018 & $\mathrm{In}_{2} \mathrm{O}_{3} / \mathrm{ZnO}$ supercycles & $A L D$ & 9.3 & $\mathrm{SiO}_{2}$ & 200 & (71) \\
\hline 2018 & $\mathrm{In}_{2} \mathrm{O}_{3} / \mathrm{ZnO}$ supercycles & $A L D$ & 6.5 & $\mathrm{SiO}_{2}$ & 300 & (69) \\
\hline 2019 & $\mathrm{In}_{2} \mathrm{O}_{3} / \mathrm{ZnO}$ supercycles & PEALD & 30.3 & $\mathrm{Al}_{2} \mathrm{O}_{3}$ & 250 & (77) \\
\hline \multirow[t]{2}{*}{2019} & $\mathrm{In}_{2} \mathrm{O}_{3} / \mathrm{ZnO} / \mathrm{Ga}_{2} \mathrm{O}_{3}$ supercycles & PEALD & 74 & $\mathrm{SiO}_{2}$ & 450 & (78) \\
\hline & & $\begin{array}{c}\text { Deposition Category: } \\
\text { Vacuum }\end{array}$ & & & & \\
\hline 2008 & $\begin{array}{c}\text { IZO / GIZO } \\
\text { or ITO / GIZO }\end{array}$ & Sputtering & $\begin{array}{l}51.3 \\
104 \\
\end{array}$ & $\mathrm{SiO}_{2}$ & 300 & (72) \\
\hline 2010 & $\mathrm{MgZnO} / \mathrm{ZnO}$ & MOCVD & 9.1 & $\mathrm{Si}_{3} \mathrm{~N}_{4}$ & 450 & (48) \\
\hline 2010 & $\mathrm{ZnO} / \mathrm{MgZnO}$ & Sputtering & $39\left(^{*}\right)$ & $n / a$ & 600 & (79) \\
\hline 2010 & $\begin{array}{c}\text { HIZO / HIZO } \\
\text { Hf content varied }\end{array}$ & Sputtering & 15 & $\mathrm{Si}_{3} \mathrm{~N}_{4} / \mathrm{SiO}_{2}$ & 370 & (17) \\
\hline 2011 & GZO / IGZO & Sputtering & 10 & $\mathrm{SiO}_{2}$ & 200 & (73) \\
\hline 2011 & IGZO /IGZO:N & Sputtering & 7.3 & $\mathrm{SiO}_{2}$ & 350 & (18) \\
\hline 2011 & ITO / ZTO & Sputtering & 43.2 & $\mathrm{SiO}_{2}$ & 500 & (58) \\
\hline 2011 & IGZO /ITO & Sputtering & 20 & $\mathrm{SiO}_{2}$ & 80 & (49) \\
\hline 2012 & $\mathrm{IZO} / \mathrm{HIZO}$ & Sputtering & 48 & $\mathrm{Si}_{3} \mathrm{~N}_{4} / \mathrm{SiO}_{2}$ & 350 & (60) \\
\hline 2012 & $\mathrm{ZnO} / \mathrm{MgZnO}$ & Sputtering & 84.2 & $\mathrm{Al}_{2} \mathrm{O}_{3}$ & 600 & (47) \\
\hline 2012 & IZO / HIZO & Sputtering & 41.4 & $\mathrm{SiO}_{2}$ & 300 & (59) \\
\hline 2012 & $I Z O / I G Z O$ & Sputtering & 47.7 & $\mathrm{SiO}_{2}$ & 250 & (61) \\
\hline 2013 & $\mathrm{SnO} / \mathrm{Cu}_{2} \mathrm{O}$ & Sputtering & 0.66 & $\mathrm{Al}_{2} \mathrm{TiO}_{5}$ & 190 & (66) \\
\hline 2013 & IGZO (O poor) /IGZO (O rich) & Sputtering & 3.65 & $\mathrm{SiO}_{2}$ & 350 & (19) \\
\hline 2014 & IGZO /IGZO:Ti & Sputtering & 63 & $\mathrm{HfO}_{2}$ & 300 & (74) \\
\hline 2014 & $I G Z O / I Z O$ & $\begin{array}{l}\text { IGZO: Spin coating } \\
\text { IZO: Sputtering }\end{array}$ & 46.7 & $\mathrm{Al}_{2} \mathrm{O}_{3}$ & 430 & (80) \\
\hline 2014 & $\ln _{2} \mathrm{O}_{3} / \operatorname{InZnO}$ & Sputtering & 37.9 & $\mathrm{ZrO}_{2}$ & 25 & (9) \\
\hline 2014 & $I Z O / Z T O$ & Sputtering & 32.3 & $\mathrm{SiO}_{2}$ & 500 & (65) \\
\hline 2016 & IGZO:H / IGZO & Sputtering & 55.3 & $\mathrm{SiO}_{2}$ & 250 & (21) \\
\hline 2016 & $\begin{array}{c}\text { ATZO / ATZO } \\
\text { varied O pressure }\end{array}$ & Sputtering & 108 & $\mathrm{SiO}_{2}$ & 150 & (20) \\
\hline 2017 & $\operatorname{In}_{2} \mathrm{O}_{3} / \mathrm{Al}_{2} \mathrm{O}_{3}$ & Sputtering & $20.5\left(^{*}\right)$ & $n / a$ & 200 & (28) \\
\hline 2019 & $I G Z O / \ln _{2} O_{3}$ & RF sputtering & $\begin{array}{l}64.4 \\
67.5 \\
79.1 \\
\end{array}$ & $\begin{array}{l}\mathrm{SiO}_{2} \\
\mathrm{HfO}_{2} \\
\mathrm{Si}_{3} \mathrm{~N}_{4}\end{array}$ & 25 & (24) \\
\hline
\end{tabular}

Table 2: Overview of selected publications on heterojunction metal oxide TFTs processed by solution processing techniques. Entries with the added asterisk (*) in the temperature field were treated by photonic curing and the stated values are the approximate substrate temperatures during the process, based on simulations.

\begin{tabular}{|c|c|c|c|c|c|c|}
\hline Year & Heterojunction Structure & Deposition Method & $\begin{array}{l}\text { Mobility } \\
\left(\mathrm{cm}^{2} / \mathrm{Vs}\right)\end{array}$ & Dielectric & $\begin{array}{c}\text { Maximum } \\
\text { Temperature }\left({ }^{\circ} \mathrm{C}\right) \\
\end{array}$ & Reference \\
\hline 2011 & $\mid Z O / A I Z O$ & Spin coating & 1.57 & $\begin{array}{l}\text { Tetraethyl- } \\
\text { orthosilicate }\end{array}$ & 350 & (62) \\
\hline 2012 & $I Z O / A I Z O$ & Spin coating & 5.62 & $\mathrm{SiO}_{2}$ & 350 & (63) \\
\hline 2013 & $I G Z O / Z T O$ & Spin coating & 2.09 & $\mathrm{SiO}_{2}$ & 450 & (10) \\
\hline 2013 & IGZO / IGZO / IGZO & Spin coating & 2.4 & $\mathrm{SiO}_{2}$ & 450 & (13) \\
\hline 2013 & $\ln _{2} \mathrm{O}_{3} / I G O$ & Spin coating & 2.6 & $\mathrm{SiO}_{2}$ & 250 & (8) \\
\hline 2014 & $I G Z O / Z T O$ & Spin coating & 1.97 & $\mathrm{SiO}_{2}$ & 450 & (11) \\
\hline 2014 & IZTO / IGZO & Spin coating & 22.16 & $\mathrm{SiO}_{2}$ & 450 & (57) \\
\hline
\end{tabular}




\begin{tabular}{|c|c|c|c|c|c|c|}
\hline 2015 & $\ln _{2} \mathrm{O}_{3} / \mathrm{Ga}_{2} \mathrm{O}_{3} / \mathrm{ZnO} / \mathrm{Ga}_{2} \mathrm{O}_{3} / \ln _{2} \mathrm{O}_{3}$ & Spin coating & $\begin{array}{l}30 \\
40 \\
\end{array}$ & $\begin{array}{c}\mathrm{SiO}_{2} \\
\mathrm{Al}_{2} \mathrm{O}_{3} / \mathrm{ZrO}_{2} \\
\end{array}$ & 200 & (14) \\
\hline 2015 & $\mathrm{ZTO} / \mathrm{In}_{2} \mathrm{O}_{3}$ & Inkjet & 8.6 & $\mathrm{SiO}_{2}$ & 400 & (12) \\
\hline 2016 & $\mathrm{SnO}_{2} / \mathrm{ZnO}$ & Spin coating & 15.4 & $\mathrm{SiO}_{2}$ & 300 & (64) \\
\hline 2017 & $\mathrm{ZTO} / \mathrm{Al}_{2} \mathrm{O}_{3}$ & Spin coating & 3.08 & $\mathrm{SiO}_{2}$ & 400 & (25) \\
\hline 2017 & $\mathrm{In}_{2} \mathrm{O}_{3} / \mathrm{ZnO}$ & $\begin{array}{c}\text { Spray pyrolysis and } \\
\text { spin coating }\end{array}$ & 45 & $\mathrm{SiO}_{2}$ & 250 & (50) \\
\hline 2017 & $\mathrm{In}_{2} \mathrm{O}_{3} / \mathrm{Li}: \mathrm{ZnO}$ & Spin coating & 11.4 & $\mathrm{SiO}_{2}$ & 200 & (53) \\
\hline 2017 & $\ln _{2} \mathrm{O}_{3} / \mathrm{GaOx}$ & Spin coating & 11 & $\mathrm{SiO}_{2}$ & 50 & (75) \\
\hline 2017 & $\mathrm{In}_{2} \mathrm{O}_{3} / \mathrm{ZnO}$ & Spin coating & 47.9 & $\mathrm{SiO}_{2}$ & 400 & (51) \\
\hline 2017 & $\mathrm{In}_{2} \mathrm{O}_{3} / \mathrm{ZnO}$ & Spin coating & 36 & $\mathrm{Al}_{2} \mathrm{O}_{3} / \mathrm{ZrO}_{2}$ & $250\left({ }^{*}\right)$ & (52) \\
\hline 2017 & $\mathrm{ZnO} / \mathrm{Ga}_{2} \mathrm{O}_{3}$ & Spray pyrolysis & 1 & $\mathrm{SiO}_{2}$ & 233 & (67) \\
\hline 2018 & ITZO / IGZO (corrugated structure) & Spin coating & 51 & $\mathrm{Al}_{2} \mathrm{O}_{3}$ & 450 & (43) \\
\hline 2018 & $\mathrm{ZnO} / \mathrm{In}_{2} \mathrm{O}_{3}$ & Spin coating & 0.5 & $\mathrm{SiO}_{2}$ & 350 & (76) \\
\hline 2019 & $\ln { }_{2} \mathrm{O}_{3} / \operatorname{In}_{2} \mathrm{O}_{3}: \mathrm{PEI}$ & Spin coating & $\begin{array}{c}10.05 \\
24.8\end{array}$ & $\begin{array}{l}\mathrm{SiO}_{2} \\
\mathrm{ZrO}_{2}\end{array}$ & $\begin{array}{l}250 \\
500\end{array}$ & (56) \\
\hline 2019 & $\mathrm{In}_{2} \mathrm{O}_{3} / \mathrm{ZnO}: \mathrm{Li} / \mathrm{In}_{2} \mathrm{O}_{3} / \mathrm{ZnO}: \mathrm{Li}$ & Spin coating & $\begin{array}{l}18 \\
25 \\
\end{array}$ & $\begin{array}{c}\mathrm{SiO}_{2} \\
\mathrm{Al}_{2} \mathrm{O}_{3} / \mathrm{ZrO}_{2} \\
\end{array}$ & 200 & (16) \\
\hline 2019 & $\mathrm{In}_{2} \mathrm{O}_{3} / \mathrm{ZnO} \mathrm{NP}: \mathrm{Al} / \mathrm{PS} / \mathrm{ZnO}$ & Spin coating & 50.7 & $\mathrm{SiO}_{2}$ & 200 & (54) \\
\hline 2019 & $\ln _{2} \mathrm{O}_{3} / \mathrm{AllnO}$ & Spin coating & 40 & $\mathrm{SiO}_{2}$ & 300 & (55) \\
\hline 2019 & $\mathrm{In}_{2} \mathrm{O}_{3} / \mathrm{IGZO}$ & Inkjet & 14.5 & $\mathrm{SiO}_{2}$ & 400 & (68) \\
\hline 2020 & $\mathrm{In}_{2} \mathrm{O}_{3} / \mathrm{ZnO}$ & Spin coating & 19 & $\mathrm{Al}_{2} \mathrm{O}_{3} / \mathrm{ZrO}_{2}$ & $200\left({ }^{*}\right)$ & (44) \\
\hline
\end{tabular}

\subsection{Distinct heterojunction layers versus mixed phase oxides}

When investigating $\mathrm{HJ}$ stacks and their impact on device performance relative to single layers MO films, one important aspect is to verify whether any improvements are indeed the results of creating distinct layers and the subsequent interface effects taking place or if the same could have been achieved simply by creating a single multicomponent mixed phase oxide instead. Such a reference test was carried out for example by Khim et al. who researched solution processed $\ln _{2} \mathrm{O}_{3} / \mathrm{ZnO} \mathrm{HJs}$ (16). As shown in Figure $5 a$, it was found that the IZO based reference devices, created by mixing the respective In- and Zn-containing precursors, showed poor transport behavior with low on-currents on the order of $10^{-6} \mathrm{~A}$ and a high turn on voltage of $26 \mathrm{~V}$. Contrary, the $\ln _{2} \mathrm{O}_{3}$ /bilayer exhibited superior properties with increased on-current $\left(10^{-3} \mathrm{~A}\right)$ and a turn on close to $0 \mathrm{~V}$. It was argued that the $200^{\circ} \mathrm{C}$ annealing temperature did not supply enough thermal energy for a complete IZO conversion, whereas electron confinement at the successfully formed $\ln _{2} \mathrm{O}_{3} / \mathrm{ZnO} \mathrm{HJ}$ was the reason for superior properties in the bilayer TFT. For a different material 
system of solution processed $\mathrm{SnO}_{2} / \mathrm{ZnO}$, Nam et al. came to similar findings where TFTs based on control ZTO films showed inferior performance compared to the $\mathrm{SnO}_{2} / \mathrm{ZnO}$ counterparts when annealed at a temperature of $300^{\circ} \mathrm{C}(64)$.

\subsection{Influence of layer thicknesses}

The layer thicknesses of the individual metal oxides that form the heterojunction in the active TFT channel have a profound impact on the overall device characteristics. For example, the effect of the front channel thickness in solution processed IZO/AIZO HJs TFTs was investigated by Jeong et al. (63). As seen in Figure $5 c$, the on/off ratio decreases with increasing IZO front channel thickness between 8 and $20 \mathrm{~nm}$. This is the result of increasing overall $\mathrm{N}_{\mathrm{e}}$ for higher IZO thicknesses, which also lead to a negative $\mathrm{V}_{\text {th }}$ shift. The same trend was reported by Liu et al. for sputtered $\ln _{2} \mathrm{O}_{3} /$ IZO HJ TFTs where $\mu_{\mathrm{FE}}$ steadily increases with higher $\ln _{2} \mathrm{O}_{3}$ thickness, albeit at the cost of an increasing subthreshold swing (SS), decreasing on/off ratio and negative $V_{\text {th }}$ shift (9). Consequently, a balanced compromise between high electron mobility and oncurrents on one side and high on/off ratio, low SS and $\mathrm{V}_{\text {th }}$ close to $0 \mathrm{~V}$ on the other side, has to be made. While Lee et al. found very similar properties for increasing ITZO film thicknesses in their ITZO/IGZO HJ devices, they made use of these findings by changing up the channel configuration (43). They created corrugated bilayer films with stripes of thin ITZO/IGZO and thick ITZO/IGZO going perpendicular to the source-drain channel orientation. This procedure allowed for devices with high on-currents and mobility $>50 \mathrm{~cm}^{2} /$ Vs while simultaneously being able to maintain low off-currents and an on/off ratio $>10^{8}$.

An investigation by Lee and Choi about inkjet printed $\mathrm{ZTO} / \mathrm{In}_{2} \mathrm{O}_{3}$ bilayer HJ TFTs examined how the increase in $\ln _{2} \mathrm{O}_{3}$ back channel thickness impacts the device performance (12). They found an initial improvement in $\mu_{\mathrm{FE}}$, on/off ratio, $\mathrm{SS}$ and $\mathrm{V}_{\mathrm{th}}$ for thinner $\mathrm{In}_{2} \mathrm{O}_{3}$ films, which was attributed to the filling of 
pores in the ZTO front channel as well as a decrease in roughness. Increasing the back channel further, however, saw a deterioration of all quantities due to the introduction of increased contact resistance, trap density and elevated roughness.

In a study on PLD deposited multilayer stacks consisting of repeated $\mathrm{ZnO} / \mathrm{SnO}_{2}$ units, the thickness of the individual layers was simultaneously varied between 0.5 and $3 \mathrm{~nm}$ while keeping the total channel thickness to $30 \mathrm{~nm}(70)$. The resulting transistors were found to exhibit a maximum $\mu_{\mathrm{FE}}$ of $43 \mathrm{~cm}^{2} / \mathrm{Vs}$ for a thickness of $1.5 \mathrm{~nm}$ for both sub-units. Further increase in thickness only lead to a decline in performance. It was argued that high mobility electron channels formed at the $\mathrm{ZnO} / \mathrm{SnO}_{2}$ interfaces and that for higher sub-unit thicknesses the number of available interfaces decreased, thus reducing $\mu_{\mathrm{FE}}$ in the device.

Krausmann et al. produced HJ TFTs based on multilayers with repeating $\ln _{2} \mathrm{O}_{3} / \mathrm{ZnO}$ units via ALD and changed the thickness ratio between $\mathrm{In}_{2} \mathrm{O}_{3}$ and $\mathrm{ZnO}$ in the repeat units (71). They found that higher amounts of defects are introduced by a higher thickness of the ZnO layers, while opposite to that thicker $\mathrm{In}_{2} \mathrm{O}_{3}$ layers resulted in higher mobilities up to $12.2 \mathrm{~cm}^{2} / \mathrm{Vs}$. However, other device parameters (on/off, $\mathrm{SS}, \mathrm{V}_{\mathrm{th}}$ ) began to deteriorate for the thickest $\mathrm{In}_{2} \mathrm{O}_{3}$ sub-units and a more balanced optimum performance was determined for a medium size $\ln _{2} \mathrm{O}_{3}$ thickness. In addition, the study revealed a gradual change in the transport properties from an initially trap-limited conduction for a low $\ln _{2} \mathrm{O}_{3} / \mathrm{ZnO}$ thickness ratio towards a percolation conduction for thicker $\ln _{2} \mathrm{O}_{3}$ layers in the repeating units. This also manifested in nearly temperature independent $\mu_{\mathrm{FE}}$ as opposed to a temperature activated behavior with for devices with the lowest $\ln _{2} \mathrm{O}_{3} / \mathrm{ZnO}$ ratios. For the same material system, with stacks of alternating $\ln _{2} \mathrm{O}_{3}$ and $\mathrm{ZnO}$ processed by ALD, Sanctis et al. varied the total number of stacks between 3 and 6 (69). With higher number of stacks an increase in channel conductivity (reduced on/off ratio, negative $V_{\text {th }}$ shift) was observed and attributed to deep-donor like states related to oxygen vacancies. An optimum number of 4 stacks was suggested based on the tradeoff between mobility, on/off ratio, subthreshold swing SS and $V_{\text {th. }}$. 


\subsection{Influence of stacking sequence}

In many bilayer HJ TFTs the more conductive MO layer is typically employed as the front channel material in direct contact with the dielectric. In this position it can serve as charge transport layer with a high $\mathrm{N}_{\mathrm{e}}$ that also can assist in trap passivation at the semiconductor/dielectric interface $(8,9,21,71)$. This was evaluated and confirmed by Sanctis et al. who fabricated multilayer stacks of repeated $\ln _{2} \mathrm{O}_{3}$ and $\mathrm{ZnO}$ layers via ALD (69). They tested the impact of starting the $\mathrm{HJ}$ sequence either with a layer of $\mathrm{ZnO}$ or $\ln _{2} \mathrm{O}_{3}$. For ZnO as the starting material, the multilayer TFTs yielded a low mobility of $1 \mathrm{~cm}^{2} / \mathrm{Vs}$, an on/off ratio of $5 \times 10^{6}$ and SS of $1.85 \mathrm{~V} / \mathrm{dec}$. All these quantities were found to be significantly improved when the sequence was reversed and $\ln _{2} \mathrm{O}_{3}$ was the starting material, giving rise to a mobility, on/off ratio and SS of $6.5 \mathrm{~cm}^{2} / \mathrm{Vs}, 5 \times 10^{7}$, and $0.7 \mathrm{~V} / \mathrm{dec}$, respectively.

Another study on the influence of the stacking sequence for the same $\ln _{2} \mathrm{O}_{3} / \mathrm{ZnO}$ material system was carried out by Khim et al. (16). Here, film stacks of up to four sequentially solution deposited single layers were formed, alternating between $\mathrm{In}_{2} \mathrm{O}_{3}$ and $\mathrm{ZnO}$ in consecutive deposition steps. Film as well as device properties were evaluated at each stage. Additionally, the films stack fabrication was either started by the deposition of $\mathrm{In}_{2} \mathrm{O}_{3}$ or $\mathrm{ZnO}$ as the initial layer. As shown in Figure $5 \mathrm{~d}$ and e, the progression of device characteristics with each new layer was vastly different. For stacks beginning with $\ln _{2} \mathrm{O}_{3}$, the mobility increases with each new steps (from 1.6 to $11.4 \mathrm{~cm}^{2} / \mathrm{Vs}$ ), making bigger jumps after a new ZnO film was deposited. In contrast to that, the devices using $\mathrm{ZnO}$ as the starting layer were limited by the mobility of a single $\mathrm{ZnO}$ film $\left(1.4 \mathrm{~cm}^{2} / \mathrm{Vs}\right)$ when $\mathrm{ZnO}$ is the topmost layer and $\mu_{\mathrm{FE}}$ even dropped about 2 orders of magnitude when $\ln _{2} \mathrm{O}_{3}$ is the topmost layer. Based on AFM investigations, it was determined that the interface roughness plays a crucial role, whereas the $\ln _{2} \mathrm{O}_{3} / \mathrm{ZnO}$ interface is favorable for charge transport but the $\mathrm{ZnO} / \mathrm{In}_{2} \mathrm{O}_{3}$ interface is doing the opposite. Consequently, sequences starting with $\ln _{2} \mathrm{O}_{3}$ inherently include more beneficial HJs that have an accumulative effect, while sequences starting with $\mathrm{ZnO}$ as the 
initial material contain more unfavorable $\mathrm{ZnO} / \mathrm{ln}_{2} \mathrm{O}_{3}$ junctions leading to more traps in the system and limited device performance.
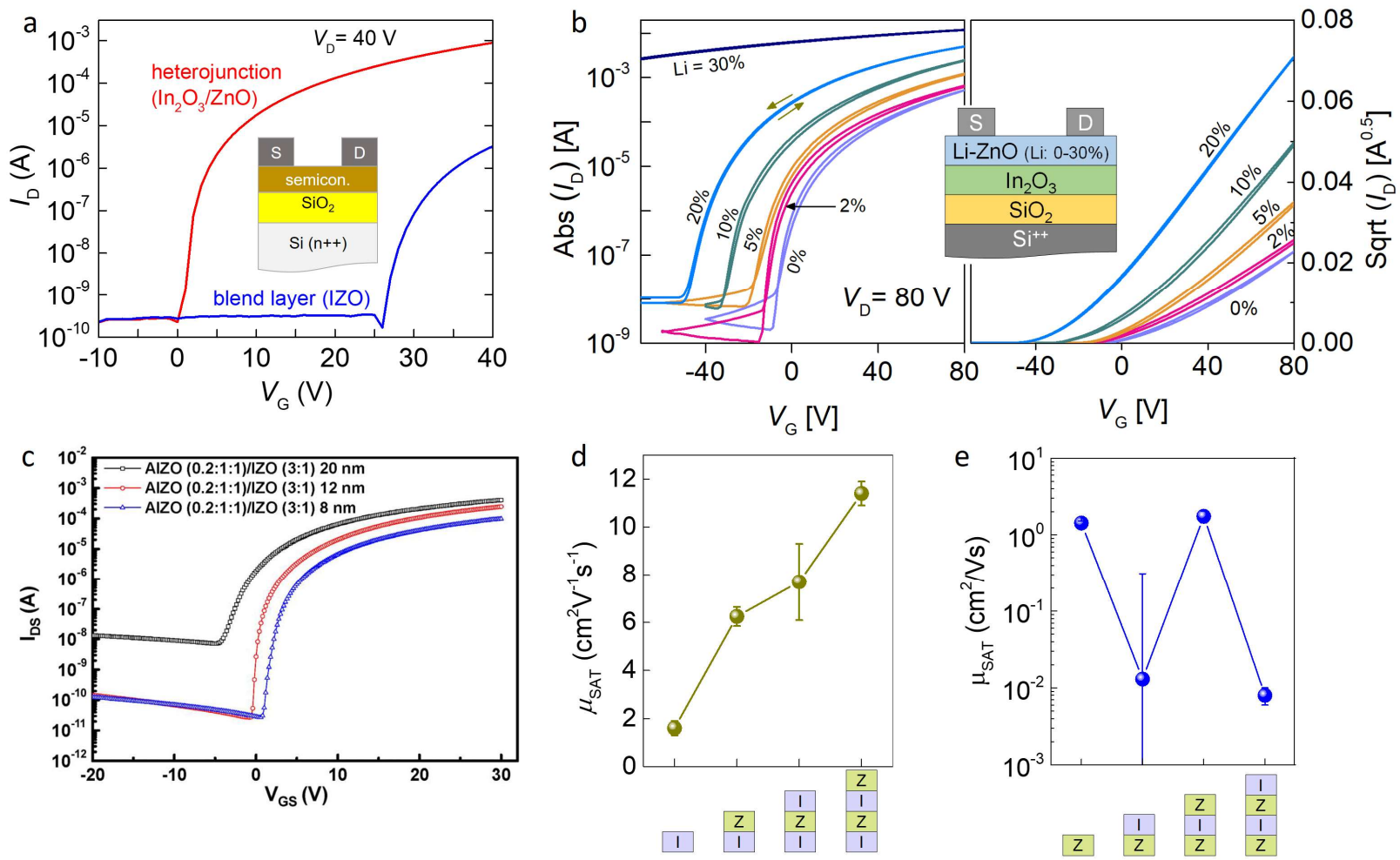

Figure 5: a) Comparison between HJ TFT with an active channel comprised of solution processed $\ln _{2} \mathrm{O}_{3} / \mathrm{ZnO}$ and a device based on a single blend layer of IZO using the same precursor components. The distinct $H J$ device exhibits superior performance. Reproduced with permission. (16) Copyright 2019, John Wiley and Sons. b) Effect of MOD on the transfer characteristics in $\mathrm{In}_{2} \mathrm{O}_{3} / \mathrm{ZnO}$ HJ TFTs via Li-doping of the ZnO layer. Reproduced with permission. (53) Copyright 2017, John Wiley and Sons. C) Evolution of transfer curves for TFTs based on solution processed IZO/AIZO HJs with increasing IZO front channel thickness between 8 and $20 \mathrm{~nm}$. (C) 2012 IEEE. Reprinted, with permission, from (63). d) and e) The effect of stacking sequence on $\mu_{F E}$ for $\mathrm{In}_{2} \mathrm{O}_{3}$ (I) and $\mathrm{ZnO}$ (Z) multilayer TFTs. Reproduced with permission. (16) Copyright 2019, John Wiley and Sons.

\subsection{Modulation doping}

Modulation doping (MOD) is a technique to improve the device performance wherein two separate semiconductors are brought into close contact, one of them is undoped (intrinsic) while the other one is intentionally doped. Given the correct relative energy levels, an electron flow (in the case of n-type doping) from the doped to the undoped layer is initiated. Because the ionized dopant sites are physically 
separated from the undoped semiconductor the charge transport in the latter is not hampered by ionized impurity scattering, enabling higher carrier mobilities. Modulation doping finds application for example in $\mathrm{GaAs} /(\mathrm{Al}, \mathrm{Ga}) \mathrm{As}$ high electron mobility transistors (29).

The introduction of MOD for MO HJ structures was simulated for the $\mathrm{ZnO} / \mathrm{ZnMgO}$ system (81) and also experimentally verified for sputtered films, where the $\mathrm{ZnMgO}$ layer was doped with a fixed concentration of $\mathrm{Al}(47,79)$. The addition of the doping layer lead to an increased sheet carrier density in addition to the polarization induced charge carries. When the Mg content in the doping layer was varied, the band gap increased with increasing $\mathrm{Mg}$ concentration and as a result the tendency of electron transfer to the $2 \mathrm{DEG}$ region increased, resulting in decreased sheet resistance and increased sheet carrier densities. According to their estimates, Chin et al. suggested that up to $61 \%$ of the charge carriers in the heterostructure originated in the doping layer (79).

Regarding solution processed $\mathrm{HJs}$, Khim et al. used Li-doped $\mathrm{ZnO}$ films to apply MOD in $\ln _{2} \mathrm{O}_{3} / \mathrm{ZnO}$ bilayer TFTs (53). Increasing the Li concentration from 0 to $20 \mathrm{wt} \%$ (in the precursor solution) was found to move the $\mathrm{ZnO}$ Fermi level $\left(\mathrm{E}_{\mathrm{F}}\right)$ closer to vacuum due to higher electron concentrations in the doped $\mathrm{ZnO}$ films. The resulting increased offset between the Fermi levels of $\ln _{2} \mathrm{O}_{3}$ and $\mathrm{ZnO}$ :Li was suggested to facilitate electron transfer from $\mathrm{ZnO}: \mathrm{Li}$ to $\ln _{2} \mathrm{O}_{3}$. Modulation doping lead to significantly reduced sheet resistance of bilayer films and the $\mu_{\mathrm{FE}}$ of HJ TFTs saw an improvement from 3.2 to $11.4 \mathrm{~cm}^{2} / \mathrm{Vs}$ for 0 to $20 \mathrm{wt} \% \mathrm{Li}$ doping. Figure $5 \mathrm{~b}$ shows the evolution of transfer curves depending on the doping concentration. In a follow up study, MOD with Li was also used to boost the performance of MO multilayer TFTs based on a $\mathrm{In}_{2} \mathrm{O}_{3} / \mathrm{ZnO} / \mathrm{In}_{2} \mathrm{O}_{3} / \mathrm{ZnO}$ channel architecture (16). Here, an increased mobility of $18 \mathrm{~cm}^{2} / \mathrm{Vs}$ and improved uniformity could be demonstrated using a $\mathrm{SiO}_{2}$ dielectric as well as $\mu_{\mathrm{FE}}$ up to $25 \mathrm{~cm}^{2} / \mathrm{Vs}$ using a high-k dielectric based on $\mathrm{AlO}_{\mathrm{x}} / \mathrm{ZrO}_{\mathrm{x}}$. These results are a good indicator for the improvements that can be achieved using MOD. 


\section{Improvements in bias stress stability for heterojunction TFTs}

For most of the targeted applications of HJMO TFTs, each single TFTs is but one device out of a large group, working together to fulfill a specific system function. One simple example is an individual transistor switching on (or off) a single pixel as part of a display that comprises many thousands of pixels. To assure the overall functionality is not compromised, it is therefore critical that each individual device stays within its operational parameters, even over prolonged times of activity and in different environments. Bias stress tests are one common way of testing a device's resistance against the application of constant biases over extended periods of time.

In a typical bias stress (BS) test, an initial transfer curve is recorded first, then a fixed set of drain voltage $V_{D}$ and gate voltage $V_{G}$ is applied over a long time frame, with intermittent transfer curve measurements at certain intervals. Depending on the polarity of $V_{G}$ and ambient conditions, different types of bias stress tests are defined:

PBS: Positive bias stress, i.e. $\mathrm{V}_{\mathrm{G}}$ is set at a positive value $(9-13,15,16,19,21,25,54,57,64,68)$.

NBS: Negative bias stress, i.e. $V_{G}$ is set at a negative value $(11,19,21,25,61,68)$.

NBIS/PBIS: Negative/positive bias stress under constant illumination $(11,25,26,61)$.

NBTS/PBTS: Negative/positive bias stress including thermal stress at elevated temperatures $(25,64)$.

As it is the most commonly performed test, we will focus on PBS in the following examination. While other values, such as the subthreshold swing SS or mobility $\mu_{F E}$ can be taken into consideration, most often the shift in threshold voltage $V_{\text {th }}$ over time is used to assess the severity of bias stress on the devices. A bias stress comparison between different literature reports is challenging as the magnitude of $V_{\text {th }}$ and its shift over time is influenced not only by the active semiconductor channel composition but also heavily by the choice of gate dielectric. Additionally, there is no clear and commonly agreed upon, framework regarding 
what voltage conditions should be applied during the testing and how long a bias stress test should be run for. While most investigations were carried out for durations below $3 \mathrm{~h}(9-13,15,19,21,25,57,68)$, only a few reports feature measurements up to $9-10 \mathrm{~h}(16,64)$ or even up to $24 \mathrm{~h}(54)$. In an effort to facilitate comparisons between bias stress tests, Lin et al. (54) proposed to calculate the electric flux density $D$ and electron trap density $N_{t r}$ according to the equations below:

$$
\begin{gathered}
D=C_{i} V_{G, P B S} \\
N_{t r}=\frac{C_{i}\left|\Delta V_{t h}\right|}{e}
\end{gathered}
$$

with $e$ being the electron charge. These quantities incorporate device and measurement parameters, namely the geometric gate capacitance $C_{i}$, the applied gate voltage $V_{G, P B S}$ as well as the shift in threshold voltages $\left(\Delta V_{t h}\right)$ between the initial and final transfer curve during the bias stress procedure. They are therefore more meaningful to compare than the raw measure of $\Delta V_{t h}$. Note, however, that this approach is not taking into account the value of $V_{D}$ during the bias stress procedure. Higher drain voltages can reduce the $\Delta V_{t h}$ through a field-assisted de-trapping mechanism (Poole-Frenkel effect) (54).

The threshold voltage shift during PBS application is typically an effect of various sources of trap states, which capture electrons from the channel when they are filled. Consequently, as the stress time increases, fewer and fewer electrons can actively contribute to the drain current, unless the gate bias is increased as well in order to compensate for this effect. As a result, the transfer curve and $V_{\text {th }}$ are shifting to more positive gate voltages in the course of a PBS experiment. Trap states can manifest as the result of various defects, such as e.g. oxygen vacancies $\mathrm{V}_{0}$, imperfect metal-oxide-metal (M-O-M) network formation or impurities (25). Another source of trap sites can be seen in the top-surface of the MO channel, which can interact with ambient gases in the environment. Specifically, the presence of oxygen during PBS causes 
adsorption on the channel surface, leading to the formation of $\mathrm{O}_{2}^{-}$species as electrons are captured from the channel.

To improve the bias stress stability of a device, each of these possible trap sites should be addressed. Inherent defects caused by e.g. incomplete M-O-M formation, remaining film porosity or impurities are often a result simply of the deposition method, where low-temperature solution processed films typically show the highest trap numbers. This might be mitigated to some degree, either by novel approaches in precursor design $(82,83)$, higher process temperatures or new post-deposition treatments $(44,52)$, or simply changing to more advanced vacuum deposition techniques. However, for various reasons this is not always feasible, e.g. regarding process constraints (temperature sensitive substrates, large scale manufacturing), or cost considerations. Furthermore, as a means to reduce the number of $V_{0}$, it is a common strategy to introduce elements with a strong affinity towards oxygen into the MO matrix, such as $\mathrm{Ga}, \mathrm{Hf}$, or Al. Together with the desired $\mathrm{V}_{\mathrm{O}}$ reduction, however, this often has the unwanted side effect to lower the charge carrier mobility $(13,21)$. It is therefore challenging to simultaneously realize high $\mu_{\text {eff }}$ and a good bias stress stability (low trap density) within a single layer MO channel.

This is where heterojunction transistors come into play because they allow to tackle both targets at the same time. A common approach is to combine a front channel material with a high mobility $\mu_{\mathrm{FE}}$ and carrier density $\mathrm{N}_{\mathrm{e}}$ together with a back channel with of lower mobility but increased stability. The higher carrier density helps to passivate large number of (interface) traps and the backchannel additionally adds separation between the charge transporting channel near the dielectric and any gas molecule interactions at the top surface. Additionally, the back channel may be processed in a way to minimize the likelihood of oxygen adsorption, e.g. by creating an oxygen rich material during the deposition (19).

Bias stress investigations were carried out in such kind of $\mathrm{HJ}$ structures with different material combinations as front and back channel. For example, Abliz et al. used a homojunction of IGZO/IGZO in 
which the front channel underwent a hydrogen plasma to increase $\mathrm{N}_{\mathrm{e}}(21)$. Similarly, Zhan et al. varied the carrier concentrations in both components of an IGZO / IGZO bilayer by adjusting the oxygen pressure during deposition via RF sputtering, thus creating an oxygen-poor but conductive front channel and an oxygen-rich IGZO back channel (19). Kim et al. used solution processed IGZO film stacks with an increased Ga content for the top-most layer (13). Other combinations rely on a front channel of $\ln _{2} \mathrm{O}_{3}$ combined with IZO (9), ZnO (16), or IGZO (68) as the back channel. Exceptionally, $\ln _{2} \mathrm{O}_{3}$ was only found as the back channel material in the study by Lee et al. (12). In a recent study, Lin et al. employed a solution processed $\mathrm{In}_{2} \mathrm{O}_{3} / \mathrm{ZnO}$ bilayer and improved upon the trap passivation by inserting both $\mathrm{ZnO}$ nanoparticles (NPs) as well a thin, UV/ozone treated layer of polystyrene (PS) in between the front and back channel (54). This hybrid organic-metal oxide multilayer approach lead to exceptional improvements in PBS stability.

As non In-containing $\mathrm{HJ}$ channel materials for bias stress tests, the combinations of $\mathrm{SnO}_{2} / \mathrm{ZnO}(64)$ or $\mathrm{ZTO} / \mathrm{Al}_{2} \mathrm{O}_{3}(25)$ were investigated. $\mathrm{Al}_{2} \mathrm{O}_{3}$ was additionally studied by $\mathrm{Ahn}$ et al. as part of their $\mathrm{ZnO} / \mathrm{Al}_{2} \mathrm{O}_{3}$ superlattices processed by ALD (15).

For all of the studies and $\mathrm{HJ}$ material combinations mentioned above, the effect was an increased resistance against bias stress. An overview comparing the results of various reports for PBS measurements of HJ TFTs is given in Figure 6 and Table 3. Figure 6a shows the trap density (as measure for the shift in transfer characteristics throughout the BS measurements) depending on the electric flux density (as a quantity describing the magnitude of applied stress). Several aspects are immediately apparent. First of all, there are two distinct groupings, one at lower values of $D$ between 0.23 to $1.4 \times 10^{-6} \mathrm{C} \mathrm{cm}^{-2}$ and a single data point at around $2.3 \times 10^{-6} \mathrm{C} \mathrm{cm}^{-2}$. This reflects the fact that to date, most BS investigations on $\mathrm{HJ}-\mathrm{MO}$ TFTs were carried out using bottom-gate top contact device architecture with a Si wafer as combined substrate and gate electrode, with a $\mathrm{SiO}_{2}$ layer atop acting as the gate dielectric. The $\mathrm{SiO}_{2}$ thickness ranges from 100 to $300 \mathrm{~nm}$ and the $V_{G, P B S}$ between 20 and $40 \mathrm{~V}$, leading to the variation seen in the electric flux. On the contrary, the investigation by Liu et al. used a $\mathrm{In}_{2} \mathrm{O}_{3} / \mathrm{InZnO} \mathrm{HJ}$ on top of solution processed $\mathrm{ZrO}_{2}$ 
dielectric with a high $\mathrm{C}_{i}$ of $775 \mathrm{nF} \mathrm{cm}{ }^{-2}$ which results in a high electric flux density over $2 \times 10^{-6} \mathrm{C} \mathrm{cm}^{-2}$ even at low $V_{G, P B S}$ of $3 V(9)$. While there are obviously differences between the $\mathrm{HJ}$ systems, as a rough trend, the resulting trap density increases with increasing electric flux, with the highest value being $1.9 \times 10^{12} \mathrm{~cm}^{-}$ 2. This intuitively makes sense as a more pronounced $\Delta V_{\text {th }}$ is expected when a higher gate bias is used during PBS. Finally, the color-coding in Figure 6a refers to the total stress time, from which it can be seen that most PBS investigations to date are kept below $3 \mathrm{~h}$ while only a few are carried out for times $>9 \mathrm{~h}$ $(16,64)$, with the longest one by Lin et al. reaching up to $24 \mathrm{~h}(54)$.
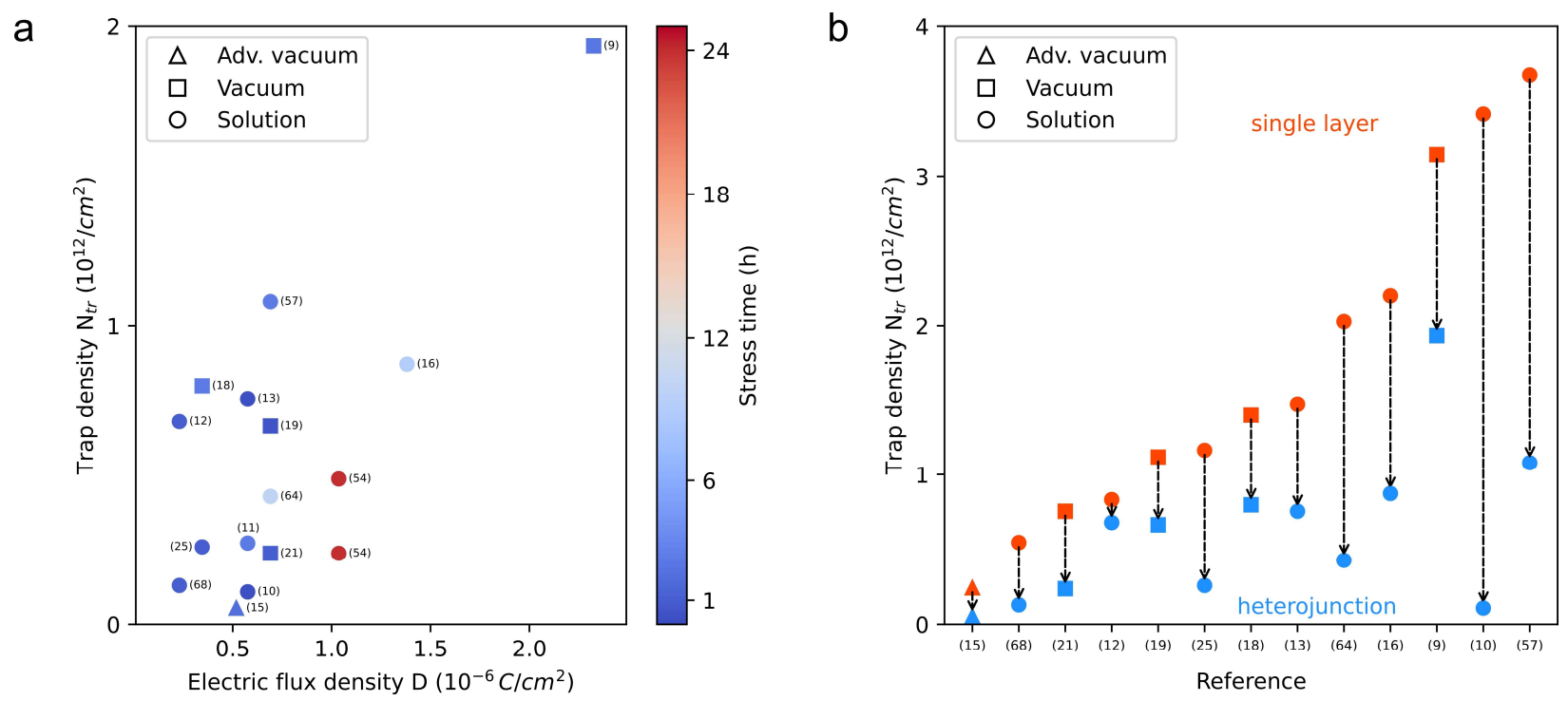

Figure 6: Overview of PBS literature results for metal oxide heterojunction TFTs. a) Trap density shifts for HJ TFTs over electric flux density applied during PBS application. The color coding of the marker indicates the total stress time up to $24 \mathrm{~h}$. b) Trap density shifts after PBS application for HJ TFTs (blue) and their single layer counterparts (red). In both panels, the shape of the marker indicates the deposition category, broken down to advanced and regular vacuum techniques as well as solution processing, as described earlier.

As pointed out before, one of the benefits of using a $\mathrm{HJ}$ approach is in the improved bias stress stability.

This is visualized in Figure $6 \mathrm{~b}$ where the resulting values of trap density for a HJ TFTs are shown in comparison to a reference device based on a single layer channel material. The single layer films span over a wide range of trap densities between 0.24 and $3.7 \times 10^{12} \mathrm{~cm}^{-2}$. Accordingly, the changes in trap density when going towards a $\mathrm{HJ}$ device vary over a similar range. Although not a clear correlation, the highest margins seem to be possible when the initial single layer TFT shows increased levels of $N_{t r}$, whereas the 
room for improvements is more limited with a low starting point. When comparing the different deposition methods (see marker shapes in Figure 6b), the lowest trap density is achieved using atomic layer deposition (15) while higher values are the result of less sophisticated methods such as sputtering techniques or via solution based processes. Especially solution-processed layers are often inherently more prone to defects due to e.g. non-fully converted precursors material, residual contaminants, or pinholes. As a result, those kinds of films can potential gain the most benefits of forming a heterojunction through the deposition of a second layer, which allows an effective defect compensation and thus more stable devices under bias stress.

Table 3: Overview of PBS investigations on metal oxide HJ structures

\begin{tabular}{|c|c|c|c|c|c|c|c|c|c|c|}
\hline Year & Heterojunction Structure & $\begin{array}{c}\text { Deposition } \\
\text { Method }\end{array}$ & Dielectric & $\begin{array}{c}\mathrm{C}_{\mathrm{i}} \\
\left(\mathrm{nF} / \mathrm{cm}^{2}\right)\end{array}$ & $\begin{array}{l}V_{G, P B S} \\
(V)\end{array}$ & $\begin{array}{l}\Delta V_{\text {th }} \\
\text { (V) }\end{array}$ & $\begin{array}{c}\text { Stress } \\
\text { Time (s) }\end{array}$ & $\begin{array}{c}D \\
\left(10^{-6} \mathrm{C} / \mathrm{cm}^{2}\right)\end{array}$ & $\begin{array}{c}N_{\mathrm{tr}} \\
\left(10^{12} / \mathrm{cm}^{2}\right)\end{array}$ & Reference \\
\hline 2011 & IGZO / IGZO:N & Sputtering & $\mathrm{SiO}_{2}$ & 34.5 & 10 & 3.7 & 10,000 & 0.34 & 0.8 & (18) \\
\hline 2013 & $\mathrm{Al}_{2} \mathrm{O}_{3} / \mathrm{ZnO}$ superlattice & ALD & $\mathrm{SiO}_{2}$ & 17.3 & 30 & 0.5 & 7,200 & 0.52 & 0.05 & (15) \\
\hline 2013 & IGZO / ZTO & Spin coating & $\mathrm{SiO}_{2}$ & 28.8 & 20 & 0.6 & 1,000 & 0.58 & 0.11 & (10) \\
\hline 2013 & IGZO / IGZO / IGZO & Spin coating & $\mathrm{SiO}_{2}$ & 28.8 & 20 & 4.2 & 1,000 & 0.58 & 0.75 & (13) \\
\hline 2013 & IGZO (O poor) /IGZO (O rich) & Sputtering & $\mathrm{SiO}_{2}$ & 34.5 & 20 & 3.08 & 1,500 & 0.69 & 0.66 & (19) \\
\hline 2014 & IGZO / ZTO & Spin coating & $\mathrm{SiO}_{2}$ & 28.8 & 20 & 1.51 & 10,000 & 0.58 & 0.27 & (11) \\
\hline 2014 & ITZO / IGZO & Spin coating & $\mathrm{SiO}_{2}$ & 34.5 & 20 & 5.01 & 10,000 & 0.69 & 1.08 & (57) \\
\hline 2014 & $\ln _{2} \mathrm{O}_{3} / \operatorname{lnZnO}$ & Sputtering & ZrOx & 775.0 & 3 & 0.4 & 9,000 & 2.33 & 1.93 & (9) \\
\hline 2015 & $\mathrm{ZTO} / \mathrm{In}_{2} \mathrm{O}_{3}$ & Inkjet & $\mathrm{SiO}_{2}$ & 11.5 & 20 & 9.45 & 3,600 & 0.23 & 0.68 & (12) \\
\hline 2016 & IGZO:H / IGZO & Sputtering & $\mathrm{SiO}_{2}$ & 34.5 & 20 & 1.1 & 3,600 & 0.69 & 0.24 & (21) \\
\hline 2016 & $\mathrm{SnO}_{2} / \mathrm{ZnO}$ & Spin coating & $\mathrm{SiO}_{2}$ & 34.5 & 20 & 1.98 & 36,000 & 0.69 & 0.43 & (64) \\
\hline 2017 & $\mathrm{ZTO} / \mathrm{Al}_{2} \mathrm{O}_{3}$ & Spin coating & $\mathrm{SiO}_{2}$ & 17.3 & 20 & 2.4 & 4,200 & 0.35 & 0.26 & (25) \\
\hline 2019 & $\begin{array}{c}\mathrm{In}_{2} \mathrm{O}_{3} / \mathrm{ZnO} \mathrm{NP}: \mathrm{Al} / \mathrm{PS} / \mathrm{ZnO} \\
\mathrm{In}_{2} \mathrm{O}_{3} / \mathrm{ZnO} \mathrm{NP} / \mathrm{PS} / \mathrm{ZnO} \\
\end{array}$ & Spin coating & $\mathrm{SiO}_{2}$ & 34.5 & 30 & $\begin{array}{c}2.25 \\
1.1 \\
\end{array}$ & 86,400 & 1.04 & $\begin{array}{l}0.48 \\
0.24 \\
\end{array}$ & (54) \\
\hline 2019 & $\mathrm{In}_{2} \mathrm{O}_{3} / \mathrm{IGZO}$ & Inkjet & $\mathrm{SiO}_{2}$ & 11.5 & 20 & 1.8 & 3,600 & 0.23 & 0.13 & (68) \\
\hline 2019 & $\mathrm{In}_{2} \mathrm{O}_{3} / \mathrm{ZnO}$ & Spin coating & $\mathrm{SiO}_{2}$ & 34.5 & 40 & 4.05 & 32,400 & 1.38 & 0.87 & (16) \\
\hline
\end{tabular}




\section{Conclusions}

The exploration of metal oxide heterojunctions and their implementations in thin-film transistors is an exciting field of current research, ranging from basic research on 2DEG formation and transport physics on one side, to simultaneous improvements of mobility and bias stress stability for potential commercial applications in various display technologies, on the other. Especially, for deposition techniques that are geared more towards low-cost and high throughput fabrication on large area substrates, the formation of $\mathrm{HJ}$ structures is an approach that offers many benefits. Due to the multitude of possible combinations of $\mathrm{HJ}$ bilayers and even more so in connection with multilayer junctions, in terms of their composition and stacking sequences, many avenues are yet to be investigated. Advancements in interface and band gap engineering of metal oxide materials for HJs promise superior device properties that are out of reach for single metal oxide materials.

In addition to the improvements of current metal oxide $\mathrm{HJ}$ concepts, the transfer of knowledge to further domains in the future is envisioned. Especially with regards to p-type oxides, the integration of organic materials into organic/inorganic hybrids or even considering sequences fully based on organic films, it will be exciting to see how far the idea of heterojunctions can be extended. As a whole, an increased usage of HJ structures is expected to open new windows of opportunities for next generation (flexible) electronic applications. 


\section{References}

1. Thomas SR, Pattanasattayavong P, Anthopoulos TD. Solution-processable metal oxide semiconductors for thin-film transistor applications. Chem Soc Rev. 2013;42(16):6910-23.

2. Petti L, Münzenrieder N, Vogt C, Faber H, Büthe L, Cantarella G, et al. Metal oxide semiconductor thin-film transistors for flexible electronics. Appl Phys Rev. 2016;3(2):021303.

3. Yeon Kwon J, Kyeong Jeong J. Recent progress in high performance and reliable n-type transition metal oxide-based thin film transistors. Semicond Sci Technol. 2015;30(2):024002.

4. Labram JG, Lin Y-H, Anthopoulos TD. Exploring Two-Dimensional Transport Phenomena in Metal Oxide Heterointerfaces for Next-Generation, High-Performance, Thin-Film Transistor Technologies. Small. 2015;11(41):5472-82.

5. Li Y, Zhao C, Zhu D, Cao P, Han S, Lu Y, et al. Recent Advances of Solution-Processed Heterojunction Oxide Thin-Film Transistors. Nanomaterials. 2020;10(5):965.

6. Hong S, Park JW, Kim HJ, Kim Y-g, Kim HJ. A review of multi-stacked active-layer structures for solution-processed oxide semiconductor thin-film transistors. J Inf Disp. 2016;17(3):93-101.

7. Tampo H, Shibata H, Maejima K, Yamada A, Matsubara K, Fons P, et al. Polarization-induced twodimensional electron gases in ZnMgO/ZnO heterostructures. Appl Phys Lett. 2008;93(20):202104.

8. Yu X, Zhou N, Smith J, Lin H, Stallings K, Yu J, et al. Synergistic approach to high-performance oxide thin film transistors using a bilayer channel architecture. ACS Appl Mater Interfaces. 2013;5(16):7983-8.

9. Liu GX, Liu A, Shan FK, Meng Y, Shin BC, Fortunato E, et al. High-performance fully amorphous bilayer metal-oxide thin film transistors using ultra-thin solution-processed ZrOx dielectric. Appl Phys Lett. 2014;105(11):113509.

10. Kim CH, Rim YS, Kim HJ. Chemical stability and electrical performance of dual-active-layered zinctin-oxide/indium-gallium-zinc-oxide thin-film transistors using a solution process. ACS Appl Mater Interfaces. 2013;5(13):6108-12.

11. Kim CH, Rim YS, Kim HJ. The effect of a zinc-tin-oxide layer used as an etch-stopper layer on the bias stress stability of solution-processed indium-gallium-zinc-oxide thin-film transistors. J Phys D: Appl Phys. 2014;47(38):385104.

12. Lee S-H, Choi W-S. Inkjet-Printed Oxide Thin-Film Transistors Using Double-Active Layer Structure. J Disp Technol. 2015;11(9):698-702.

13. Kim DJ, Rim YS, Kim HJ. Enhanced electrical properties of thin-film transistor with self-passivated multistacked active layers. ACS Appl Mater Interfaces. 2013;5(10):4190-4.

14. Lin Y-H, Faber H, Labram JG, Stratakis E, Sygellou L, Kymakis E, et al. High Electron Mobility ThinFilm Transistors Based on Solution-Processed Semiconducting Metal Oxide Heterojunctions and QuasiSuperlattices. Adv Sci. 2015;2(7):1500058.

15. Ahn CH, Senthil K, Cho HK, Lee SY. Artificial semiconductor/insulator superlattice channel structure for high-performance oxide thin-film transistors. Sci Rep. 2013;3:2737.

16. Khim D, Lin Y-H, Anthopoulos TD. Impact of Layer Configuration and Doping on Electron Transport and Bias Stability in Heterojunction and Superlattice Metal Oxide Transistors. Adv Funct Mater. 2019;29(38):1902591.

17. Park JC, Kim S, Kim S, Kim C, Song I, Park Y, et al. Highly stable transparent amorphous oxide semiconductor thin-film transistors having double-stacked active layers. Adv Mater. 2010;22(48):5512-6.

18. Liu P-T, Chou Y-T, Teng L-F, Li F-H, Fuh C-S, Shieh H-PD. Ambient Stability Enhancement of ThinFilm Transistor With InGaZnO Capped With InGaZnO:N Bilayer Stack Channel Layers. IEEE Electron Device Lett. 2011;32(10):1397-9.

19. Zhan R, Dong C, Liu P-T, Shieh H-PD. Influence of channel layer and passivation layer on the stability of amorphous InGaZnO thin film transistors. Microelectron Reliab. 2013;53(12):1879-85. 
20. Cong $Y$, Han D, Zhou X, Huang L, Shi $P$, Yu W, et al. High-Performance Al-Sn-Zn-O Thin-Film Transistor With a Quasi-Double-Channel Structure. IEEE Electron Device Lett. 2016;37(1):53-6.

21. Abliz A, Wang J, Xu L, Wan D, Liao L, Ye C, et al. Boost up the electrical performance of InGaZnO thin film transistors by inserting an ultrathin InGaZnO:H layer. Appl Phys Lett. 2016;108(21):213501.

22. Ohtomo A, Hwang HY. A high-mobility electron gas at the LaAlO3-SrTiO3 heterointerface. Nature 2004;427:423-6.

23. Tampo H, Matsubara K, Yamada A, Shibata H, Fons P, Yamagata M, et al. High electron mobility $\mathrm{Zn}$ polar $\mathrm{ZnMgO} / \mathrm{ZnO}$ heterostructures grown by molecular beam epitaxy. J Cryst Growth. 2007;301302:358-61.

24. He J, Li G, Lv Y, Wang C, Liu C, Li J, et al. Defect Self-Compensation for High-Mobility Bilayer InGaZnO/In2O3 Thin-Film Transistor. Adv Electron Mater. 2019;5(6).

25. Cho SW, Kim DE, Kim KS, Jung SH, Cho HK. Towards environmentally stable solution-processed oxide thin-film transistors: a rare-metal-free oxide-based semiconductor/insulator heterostructure and chemically stable multi-stacking. J Mater Chem C. 2017;5(40):10498-508.

26. Oh H, Ko Park S-H, Hwang C-S, Yang S, Ki Ryu M. Enhanced bias illumination stability of oxide thin film transistor through insertion of ultrathin positive charge barrier into active material. Appl Phys Lett. 2011;99(2):022105.

27. Nayak PK, Wang Z, Anjum DH, Hedhili MN, Alshareef HN. Highly stable thin film transistors using multilayer channel structure. Appl Phys Lett. 2015;106(10):103505.

28. Lee SY, Kim J, Park A, Park J, Seo H. Creation of a Short-Range Ordered Two-Dimensional Electron Gas Channel in Al2O3/In2O3 Interfaces. ACS Nano. 2017;11(6):6040-7.

29. Drummond TJ, Masselink WT, Morkoc H. Modulation-Doped GaAs/(Al, Ga)As Heterojunction Field-Effect Transistors: MODFETs. Proc IEEE. 1986;74(6):773-822.

30. Ambacher O, Smart J, Shealy JR, Weimann NG, Chu K, Murphy M, et al. Two-dimensional electron gases induced by spontaneous and piezoelectric polarization charges in N- and Ga-face AlGaN/GaN heterostructures. J Appl Phys. 1999;85(6):3222-33.

31. Schlom DG, Pfeiffer LN. Oxide electronics: Upward mobility rocks! Nat Mater. 2010;9(11):881-3.

32. Edahiro $\mathrm{T}$, Fujimura $\mathrm{N}$, Ito $\mathrm{T}$. Formation of two-dimensional electron gas and the magnetotransport behavior of ZnMnO/ZnO heterostructure. J Appl Phys. 2003;93(10):7673-5.

33. Tsukazaki A, Ohtomo A, Kita T, Ohno Y, Ohno H, Kawasaki M. Quantum Hall Effect in Polar Oxide Heterostructures. Science. 2007;315(5817):1388-91.

34. Yano M, Hashimoto K, Fujimoto K, Koike K, Sasa S, Inoue M, et al. Polarization-induced twodimensional electron gas at Zn1-xMgxO/ZnO heterointerface. J Cryst Growth. 2007;301-302:353-7.

35. Koike K, Hama K, Nakashima I, Takada G-y, Ozaki M, Ogata K-i, et al. Piezoelectric Carrier Confinement by Lattice Mismatch at ZnO/Zn0.6Mg0.40 Heterointerface. Jpn J Appl Phys. 2004;43(No. 10B):L1372-L5.

36. Tampo H, Shibata H, Matsubara K, Yamada A, Fons P, Niki S, et al. Two-dimensional electron gas in $\mathrm{Zn}$ polar $\mathrm{ZnMgO} / \mathrm{ZnO}$ heterostructures grown by radical source molecular beam epitaxy. Appl Phys Lett. 2006;89(13):132113.

37. Nakano M, Tsukazaki A, Ohtomo A, Ueno K, Akasaka S, Yuji H, et al. Electric-field control of twodimensional electrons in polymer-gated-oxide semiconductor heterostructures. Adv Mater. 2010;22(8):876-9.

38. Falson J, Maryenko D, Kozuka Y, Tsukazaki A, Kawasaki M. Magnesium Doping Controlled Density and Mobility of Two-Dimensional Electron Gas in MgxZn_(1-x)O/ZnO Heterostructures. Appl Phys Express. 2011;4(9).

39. Tsukazaki A, Akasaka S, Nakahara K, Ohno Y, Ohno H, Maryenko D, et al. Observation of the fractional quantum Hall effect in an oxide. Nat Mater. 2010;9(11):889-93. 
40. Koike K, Nakashima I, Hashimoto K, Sasa S, Inoue M, Yano M. Characteristics of a $\mathrm{Zn0.7Mg0.30/ZnO} \mathrm{heterostructure} \mathrm{field-effect} \mathrm{transistor} \mathrm{grown} \mathrm{on} \mathrm{sapphire} \mathrm{substrate} \mathrm{by} \mathrm{molecular-beam}$ epitaxy. Appl Phys Lett. 2005;87(11):112106.

41. Sasa S, Ozaki M, Koike K, Yano M, Inoue M. High-performance $\mathrm{ZnO} / \mathrm{ZnMgO}$ field-effect transistors using a hetero-metal-insulator-semiconductor structure. Appl Phys Lett. 2006;89(5):053502.

42. Sasa S, Hayafuji T, Kawasaki M, Koike K, Yano M, Inoue M. Improved Stability of High-Performance ZnO/ZnMgO Hetero-MISFETs. IEEE Electron Device Lett. 2007;28(7):543-5.

43. Lee M, Jo JW, Kim YJ, Choi S, Kwon SM, Jeon SP, et al. Corrugated Heterojunction Metal-Oxide Thin-Film Transistors with High Electron Mobility via Vertical Interface Manipulation. Adv Mater. 2018:e1804120.

44. Yarali E, Faber H, Yengel E, Seitkhan A, Loganathan K, Harrison GT, et al. Low-Voltage Heterojunction Metal Oxide Transistors via Rapid Photonic Processing. Adv Electron Mater. 2020;6(6):2000028.

45. Chin H-A, Cheng IC, Huang C-I, Wu Y-R, Lu W-S, Lee W-L, et al. Two dimensional electron gases in polycrystalline $\mathrm{MgZnO} / \mathrm{ZnO}$ heterostructures grown by rf-sputtering process. J Appl Phys. 2010;108(5).

46. Huang C-I, Chin H-A, Wu Y-R, Cheng IC, Chen JZ, Chiu K-C, et al. Mobility Enhancement of Polycrystalline MgZnO/ZnO Thin Film Layers With Modulation Doping and Polarization Effects. IEEE Trans Electron Devices. 2010;57(3):696-703.

47. Cheng I-C, Wang B-S, Hou H-H, Chen J-Z. MgZnOZnO Heterostructure Field-Effect Transistors Fabricated by RF-Sputtering. ECTS Transactions. 2012;50(8):83-93.

48. Remashan K, Choi YS, Park SJ, Jang JH. High Performance MOCVD-Grown ZnO Thin-Film Transistor with a Thin MgZnO Layer at Channel/Gate Insulator Interface. J Electrochem Soc. 2010;157(12):H1121.

49. Taniguchi S, Yokozeki M, Ikeda M, Suzuki T-k. Transparent Oxide Thin-Film Transistors Using n(In2O3)0.9(SnO2)0.1/InGaZnO4Modulation-Doped Heterostructures. Jpn J Appl Phys. 2011;50(4):04df11. 50. Faber H, Das S, Lin Y-H, Pliatsikas N, Zhao K, Kehagias T, et al. Heterojunction oxide thin-film transistors with unprecedented electron mobility grown from solution. Sci Adv. 2017;3(3):e1602640.

51. Tetzner K, Isakov I, Regoutz A, Payne DJ, Anthopoulos TD. The impact of post-deposition annealing on the performance of solution-processed single layer In2O3 and isotype In2O3/ZnO heterojunction transistors. J Mater Chem C. 2017;5(1):59-64.

52. Tetzner K, Lin Y-H, Regoutz A, Seitkhan A, Payne DJ, Anthopoulos TD. Sub-second photonic processing of solution-deposited single layer and heterojunction metal oxide thin-film transistors using a high-power xenon flash lamp. J Mater Chem C. 2017;5(45):11724-32.

53. Khim D, Lin Y-H, Nam S, Faber H, Tetzner K, Li R, et al. Modulation-Doped In2O3/ZnO Heterojunction Transistors Processed from Solution. Adv Mater. 2017;29(19):1605837.

54. Lin Y-H, Li W, Faber H, Seitkhan A, Hastas NA, Khim D, et al. Hybrid organic-metal oxide multilayer channel transistors with high operational stability. Nat Electron. 2019;2(12):587-95.

55. Liu L, Chen S, Liang X, Pei Y. Solution Processed AllnO/In2O3 Heterostructure Channel Thin Film Transistor with Enhanced Performance. Adv Electron Mater. 2019;5(12):1900550.

56. Chen Y, Huang W, Sangwan VK, Wang B, Zeng L, Wang G, et al. Polymer Doping Enables a TwoDimensional Electron Gas for High-Performance Homojunction Oxide Thin-Film Transistors. Adv Mater. 2019;31(4):e1805082.

57. Rim YS, Chen H, Kou X, Duan HS, Zhou H, Cai M, et al. Boost up mobility of solution-processed metal oxide thin-film transistors via confining structure on electron pathways. Adv Mater. 2014;26(25):4273-8.

58. Kim J-I, Hwan Ji K, Yoon Jung H, Yeob Park S, Choi R, Jang M, et al. Improvement in both mobility and bias stability of $\mathrm{ZnSnO}$ transistors by inserting ultra-thin InSnO layer at the gate insulator/channel interface. Appl Phys Lett. 2011;99(12):122102. 
59. Chong E, Lee SY. Influence of a highly doped buried layer for HfInZnO thin-film transistors. Semicond Sci Technol. 2012;27(1):012001.

60. Kim HS, Park JS, Jeong HK, Son KS, Kim TS, Seon JB, et al. Density of states-based design of metal oxide thin-film transistors for high mobility and superior photostability. ACS Appl Mater Interfaces. 2012;4(10):5416-21.

61. Park JC, Lee H-N. Improvement of the Performance and Stability of Oxide Semiconductor ThinFilm Transistors Using Double-Stacked Active Layers. IEEE Electron Device Lett. 2012;33(6):818-20.

62. Kim KM, Jeong WH, Kim DL, Rim YS, Choi Y, Ryu M-K, et al. Low-Temperature Solution Processing of AllnZnO/InZnO Dual-Channel Thin-Film Transistors. IEEE Electron Device Lett. 2011;32(9):1242-4.

63. Jeong WH, Kim KM, Kim DL, Rim YS, Kim HJ. The Effects of Dual-Active-Layer Modulation on a LowTemperature Solution-Processed Oxide Thin-Film Transistor. IEEE Trans Electron Devices. 2012;59(8):2149-52.

64. Nam S, Yang J-H, Cho SH, Choi JH, Kwon O-S, Park E-S, et al. Solution-processed indium-free $\mathrm{ZnO} / \mathrm{SnO} 2$ bilayer heterostructures as a low-temperature route to high-performance metal oxide thinfilm transistors with excellent stabilities. J Mater Chem C. 2016;4(47):11298-304.

65. Jung HY, Kang Y, Hwang AY, Lee $\mathrm{CK}$, Han S, Kim DH, et al. Origin of the improved mobility and photo-bias stability in a double-channel metal oxide transistor. Sci Rep. 2014;4:3765.

66. Al-Jawhari HA, Caraveo-Frescas JA, Hedhili MN, Alshareef HN. P-type Cu(2)O/SnO bilayer thin film transistors processed at low temperatures. ACS Appl Mater Interfaces. 2013;5(19):9615-9.

67. Zeumault A, Subramanian V. Use of high-k encapsulation to improve mobility in trap-limited metal-oxide semiconductors. Phys Status Solidi B. 2017;254(10):1700124.

68. Liang $K$, Wang $Y$, Shao S, Luo M, Pecunia V, Shao L, et al. High-performance metal-oxide thin-film transistors based on inkjet-printed self-confined bilayer heterojunction channels. J Mater Chem $\mathrm{C}$. 2019;7(20):6169-77.

69. Sanctis S, Krausmann J, Guhl C, Schneider JJ. Stacked indium oxide/zinc oxide heterostructures as semiconductors in thin film transistor devices: a case study using atomic layer deposition. J Mater Chem C. 2018;6(3):464-72.

70. Lee S-J, Hwang C-S, Pi J-E, Yang J-H, Byun C-W, Chu HY, et al. High Performance Amorphous Multilayered $\mathrm{ZnO}-\mathrm{SnO} 2$ Heterostructure Thin-Film Transistors: Fabrication and Characteristics. ETRI Journal. 2015;37(6):1135-42.

71. Krausmann J, Sanctis S, Engstler J, Luysberg M, Bruns M, Schneider JJ. Charge Transport in LowTemperature Processed Thin-Film Transistors Based on Indium Oxide/Zinc Oxide Heterostructures. ACS Appl Mater Interfaces. 2018;10(24):20661-71.

72. Kim SI, Kim CJ, Song I, Kim SW, Yin H, Lee E, et al. High Performance Oxide Thin Film Transistors with Double Active Layers. 2008 IEEE Int Electron Dev Meeting. 2008:1-4.

73. Chong E, Jeon YW, Chun YS, Kim DH, Lee SY. Localization effect of a current-path in amorphous In-Ga-Zn-O thin film transistors with a highly doped buried-layer. Thin Solid Films. 2011;519(13):434750.

74. Hsu H-H, Chang C-Y, Cheng C-H, Chiou S-H, Huang C-H. High Mobility Bilayer Metal-Oxide Thin Film Transistors Using Titanium-Doped InGaZnO. IEEE Electron Device Lett. 2014;35(1):87-9.

75. Lee W, Kim J, Kim Y-H. High-performance InOx/GaOx bilayer channel thin-film transistors made using persistent high-surface-energy induced by photochemical activation. J Alloys Compd. 2017;723:627-

32.

76. Lee $\mathrm{H}$, Zhang $\mathrm{X}$, Kim JW, Kim EJ, Park J. Investigation of the Electrical Characteristics of Bilayer $\mathrm{ZnO} / \operatorname{In}(2) \mathrm{O}(3)$ Thin-Film Transistors Fabricated by Solution Processing. Materials. 2018;11(11).

77. Lee J-M, Lee H-J, Pi J-E, Yang J-H, Lee JH, Ahn S-D, et al. All-oxide thin-film transistors with channels of mixed InOx-ZnOy formed by plasma-enhanced atomic layer deposition process. J Vac Sci Technol, A. 2019;37(6). 
78. Sheng J, Hong T, Lee HM, Kim K, Sasase M, Kim J, et al. Amorphous IGZO TFT with High Mobility of approximately $70 \mathrm{~cm}(2) /(\mathrm{V} s)$ via Vertical Dimension Control Using PEALD. ACS Appl Mater Interfaces. 2019;11(43):40300-9.

79. Chin HA, Cheng IC, Li CK, Wu YR, Chen JZ, Lu WS, et al. Electrical properties of modulation-doped rf-sputtered polycrystalline MgZnO/ZnO heterostructures. J Phys D: Appl Phys. 2011;44(45):455101.

80. Kim KT, Kim J, Kim Y-H, Park SK. In-Situ Metallic Oxide Capping for High Mobility SolutionProcessed Metal-Oxide TFTs. IEEE Electron Device Lett. 2014;35(8):850-2.

81. Cohen DJ, Barnett SA. Predicted electrical properties of modulation-doped ZnO-based transparent conducting oxides. J Appl Phys. 2005;98(5).

82. Kim MG, Kanatzidis MG, Facchetti A, Marks TJ. Low-temperature fabrication of high-performance metal oxide thin-film electronics via combustion processing. Nat Mater. 2011;10(5):382-8.

83. Lin $\mathrm{Y}-\mathrm{H}$, Faber $\mathrm{H}$, Zhao K, Wang $\mathrm{Q}$, Amassian A, McLachlan $\mathrm{M}$, et al. High-performance ZnO transistors processed via an aqueous carbon-free metal oxide precursor route at temperatures between 80-180 degrees C. Adv Mater. 2013;25(31):4340-6.

\section{Acknowledgements}

This publication is based upon work supported by the King Abdullah University of Science and Technology (KAUST) Office of Sponsored Research (OSR) under Award No: OSR-2018-CARF/CCF-3079. 